Illinois State University

ISU ReD: Research and eData

Theses and Dissertations

3-3-2015

\title{
In vivo modulation of rhythmically active neural networks in the crustacean stomatogastric ganglion
}

Alexandra Mead Yarger

Illinois State University, ayarger@ilstu.edu

Follow this and additional works at: https://ir.library.illinoisstate.edu/etd

Part of the Biology Commons

\section{Recommended Citation}

Yarger, Alexandra Mead, "In vivo modulation of rhythmically active neural networks in the crustacean stomatogastric ganglion" (2015). Theses and Dissertations. 331.

https://ir.library.illinoisstate.edu/etd/331

This Thesis is brought to you for free and open access by ISU ReD: Research and eData. It has been accepted for inclusion in Theses and Dissertations by an authorized administrator of ISU ReD: Research and eData. For more information, please contact ISUReD@ilstu.edu. 


\title{
IN VIVO MODULATION OF RHYTHMICALLY ACTIVE NEURAL NETWORKS IN THE CRUSTACEAN STOMATOGASTRIC GANGLION
}

\author{
Alexandra Mead Yarger \\ 60 Pages \\ May 2015 \\ Rhythmic motor patterns are found throughout all living organisms and are \\ responsible for maintaining some of our most fundamental behaviors. The motor circuits \\ responsible for producing these behaviors are flexible and able to adapt to changing \\ internal and environmental conditions, yet stable enough to maintain function within \\ certain boundaries. Central pattern generators (CPGs) which are the primary source of \\ this stability reliably maintain activity patterns and thus the behaviors they drive. The \\ crab stomatogastric nervous system contains the well-characterized gastric mill \\ (chewing) and pyloric (filtering of food) CPGs. In vitro, the pyloric rhythm is stereotyped \\ with little variation over time. Temperature, inter-circuit interactions and \\ neuromodulation can influence the rhythm, but most variation occurs between \\ individuals, not within (Tang et al., 2012; Bucher et al.,). In vivo, the range of variation of \\ the rhythm and the extent of external influences are, with few exceptions unknown \\ (Hedrich et al., 2011; Soofi et al., 2014). \\ Using long-term recordings at constant temperature we identified the range and \\ sources of variability of the pyloric and gastric mill rhythms in vivo. A 12 hour light- \\ driven cycle influences the frequency of both the pyloric and gastric mill rhythms;
}


However this can be overridden by other sensory influences, including feeding. Feeding also alters the structure of the pyloric rhythm as we as increasing its frequency. The pyloric and gastric mill rhythms exhibit intercircuit interactions consistent with those previously observed in vitro (Marder et al., 2005). Non-canonical rhythms which had previously not been shown to occur naturally were also observed. 
IN VIVO MODULATION OF RHYTHMICALLY ACTIVE NEURAL NETWORKS IN THE CRUSTACEAN STOMATOGASTRIC GANGLION

ALEXANDRA MEAD YARGER

A Thesis Submitted in Partial

Fulfillment of the Requirements for the Degree of

MASTER OF SCIENCE

School of Biological Sciences

ILLINOIS STATE UNIVERSITY

2015 
Copyright 2015 Alexandra Mead Yarger 
IN VIVO MODULATION OF RHYTHMICALLY ACTIVE NEURAL NETWORKS IN THE CRUSTACEAN STOMATOGASTRIC GANGLION

ALEXANDRA MEAD YARGER

COMMITTEE MEMBERS:

Wolfgang Stein, Chair

Paul Garris

Steven Juliano 


\section{ACKNOWLEDGMENTS}

The writer wishes to thank Carola Städele, Chris Goldsmith, Marissa Cruz, and

Lena Yolanda Braun for their help and input. This work is supported by the School of Biological Sciences (AY), NSF IOS-1354932 and a startup grant from Illinois State University and the Central Illinois Neuroscience Foundation (WS).

A.M.Y. 


\section{CONTENTS}

\section{Page}

ACKNOWLEDGMENTS

CONTENTS

TABLES

iv

FIGURES

V

\section{CHAPTER}

I. INTRODUCTION

Objective

Hypothesis

Introduction

Sub-Objectives

$\begin{array}{ll}\text { II. METHODS } & 14\end{array}$

$\begin{array}{ll}\text { Dissection } & 14\end{array}$

Light Cycle Experiments 16

$\begin{array}{ll}\text { Sensory Manipulations } & 17\end{array}$

$\begin{array}{ll}\text { Statistical Analysis } & 18\end{array}$

$\begin{array}{ll}\text { III. RESULTS } & 19\end{array}$

No Consistent Daily Rhythmicity Exists for Locomotion 19

Pyloric and Gastric Mill Frequencies are Highly Variable, but with No

Obvious Daily Pattern within Individuals

There is No Difference in Pyloric and Gastric Mill Frequency Between

Day and Night

There is an Increase in Pyloric and Gastric Mill Frequency during

Dawn and Dusk

Increased Frequency during Dawn and Dusk Does Not Persist Under

Constant Light Conditions

The Structure of the Pyloric Rhythm Remains Stable Across Pyloric 
Frequencies 28

The Gastric Mill and Pyloric Frequencies are Highly Correlated 31

The Pyloric and Gastric Mill Rhythms Interact Similarly In Vivo and In

Vitro

Feeding Immediately Influences the Activity of the Pyloric Rhythm and Persists for Several Days

Non-canonical Pyloric Rhythms Occur Sporadically and Can be Associated with Gastric Mill Rhythms

$\begin{array}{ll}\text { IV. DISCUSSION } & 40\end{array}$

Daily Rhythmicity of Locomotion 41

Daily Rhythmicity of Motor Patterns in the STNS 44

Long-term Pyloric and Gastric Mill Frequency Variability 46

The Structure of the Pyloric Rhythm Remains Stable Across Pyloric

Frequencies 47

The Pyloric and Gastric Mill Rhythms Interact Similarly In Vivo and In Vitro

Feeding Immediately Influences the Structure and Frequency of the Pyloric Rhythm

Non-canonical Pyloric Rhythms Occur Sporadically and Can be Associated with Gastric Mill Rhythms 


\section{TABLES}

Table $\quad$ Page

1. Pyloric and gastric mill frequency averages in $\mathrm{Hz}$ at different times of day 23

2. Summary statistics for burst structure of LP 


\section{FIGURES}

$\begin{array}{lll}\text { Figure } & \text { Page }\end{array}$

1. Diagram showing the crab stomatogastric nervous system 6

2. Example in vivo extracellular recording of the lvn showing the pyloric Rhythm

3. Example in vivo extracellular recording of the $l v n$ showing pyloric and Gastric mill rhythms.

4. Modulators affecting the stomatogastric ganglion (STG) 9

5. Extracellular in vivo recording setup 15

6. In vivo leg recording setup 16

7. Example in vivo locomotor activity 20

8. Example in vivo pyloric frequency 22

9. Normalized pyloric frequency at different times of day under LD conditions 25

10. Normalized gastric mill frequency at different times of day under LD Conditions

11. Pyloric frequency at different times of day under DD conditions 27

12. Pyloric frequency at different times of day under LL conditions 28

13. Example in vivo LP duty cycle 30

14. Correlations between gastric mill and pyloric frequencies 32

15. Pyloric and gastric mill rhythm in vivo interactions 33

16. Example in vivo gastric mill frequency from one animal showing two Types of gastric mill rhythms 
17. Example in vivo pyloric frequency after feeding

18. Different aspects of the pyloric rhythm before and after feeding

19. A typical in vivo canonical pyloric rhythm as well as examples of noncanonical Pyloric rhythms

20. Simplified schematic of some of the connections between pyloric and Gastric mill circuit neurons 


\section{CHAPTER I \\ INTRODUCTION}

\section{Objective}

We used an in vivo approach in order to gain a comprehensive understanding of the long-term environmental influences on rhythmic motor patterns of the crab Cancer borealis.

\section{Hypothesis}

The pyloric and gastric mill rhythms, two continuously active motor behaviors fluctuate in a predictable pattern throughout the day. Long-term influences on these behaviors such as circadian rhythms as well as short-term feedback and motivation interact in vivo to modulate their motor patterns.

\section{Introduction}

Rhythmic behaviors are found throughout living organisms, from the 17 year emergence pattern of the cicada to the wing beat of a hummingbird. In humans we can see examples of rhythmic motor patterns in some of our most fundamental behaviors such as swallowing, breathing and walking. The consequences of dysfunction of such rhythmic behaviors can be devastating and failures to generate or control them can lead to a myriad of disablements. One example is sudden infant death syndrome where the breathing system 
switches from a rhythmic state to a tonic one and causes breathing to ceases during sleep (Feldman et al., 2006). All motor behaviors are initiated and controlled by the nervous system so, it is important to explore how the nervous system functions to better understand behavior. Not only that, we must also look into how the nervous system responds to complex environments and what mechanisms are employed to produce a stable yet suitable modification to its motor output.

Rhythmic behaviors are achieved through the activity of neural networks, which drive the timing of motor neuron output known as central pattern generators (CPG). CPGs are able to generate rhythmicity in the absence of any phasic sensory input either by the endogenous bursting properties of individual neurons or through the synaptic interactions between neurons (Binder and Hirokawa, 2009). The majority of research performed on rhythmic motor circuits has been accomplished in vitro for the obvious reason that the systems are more easily accessible in that condition. Much is already known at the cellular level about the mechanisms of generation of fast motor patterns (heartbeat, locomotion, etc.), as well as plasticity in the motor circuits themselves (Marder and Calabrese, 1996; Harris-Warrick, 2011; Marder, 2012). Relatively little is known about the long-term regulation and stability of the motor patterns.

CPGs are capable of producing stable rhythmicity without phasic sensory input, but motor circuits can also be flexible and adapt to changing internal and environmental conditions. The activity of CPGs though generally thought of as stereotyped and stable, can be adjusted in response to sensory feedback, interaction with other neural circuits (intercircuit interactions), hormonal regulation and modulatory input neurons (Marder and Calabrese, 
1996; Marder, 2012; Taghert and Nitabach, 2012). The ability to modulate the neural output of CPGs is an important aspect of CPG functionality, (Blitz and Nusbaum, 2011) as it adapts the neuronal activity to varying external and internal conditions. The presence of different modulatory conditions can not only change the activity patterns of single neurons, but also elicit changes in whole networks of neurons and thus the corresponding motor output (HarrisWarrick and Marder, 1991) and behavior (Diehl et al., 2013).

It is clear from in vitro studies that all named influences contribute to the regulation of activity patterns of rhythmic motor circuits. Because rhythmic motor patterns are easily quantified, fast sensory influences, for example, and their role in shaping CPG output have been studied extensively (Stein 2014). During locomotion, proprioceptive feedback has been shown in multiple organisms including cat, lamprey and stick insect to modulate CPG timing and phase on a cycle by cycle basis (Conway et al., 1987; Antri et al., 2009; Buchanan, 2011; Akay et al., 2007). Leech heartbeat can also be quickly modified in response to temperature, sensory stimulation (mechanical stimuli applied to the body), and locomotor activity (Arbas and Calabrese, 1984). In addition to these direct and fast sensory influences, neurons extrinsic to the CPGs also have access to and directly affect the timing of CPG networks. Modulatory projection neurons, for example, cause fast- and slow-acting modifications to rhythmic motor patterns (Stein 2014). In the crustacean stomatogastic nervous system (STNS) activation of different modulatory pathways not only elicit short-lasting differences in motor neuron burst patterns, but also longer lasting changes in the behavioral output (Diehl et al., 2013).

There are several sensory and hormonal influences, which cause a longer lasting modulation of the activity of motor circuits. In fact, hormonal and environmental signals 
often interact: In mammals, for example, melatonin release controls the sleep/wake cycle and is entrained by daily light changes (Zhdanova et al., 1997). Light and food availability have also been indicated to exert long-term effects on the behavior of invertebrates. The motor patterns in the STNS of crabs, for example, are influenced by the tides, feeding, and light (Fleischer, 1981; Clemens et al., 1998). In the latter case, red pigment concentrating hormone $(\mathrm{RPCH})$, a neuropeptide which acts as a filter to regulate the amount of light reaching the retina, fluctuates with daily light cycles (Strauss and Dircksen, 2010; Thirumalai et al., 2006). RCPH has also been shown to influence the motor activity of rhythmic motor circuits in the STNS (Li et al., 2002; Fleischer, 1981; Thirumalai et al., 2006; Billimoria et al., 2005; Hooper and Marder, 1984; Skiebe, 1994; Richards and Marder, 2000). Yet, since these experiments were performed in the isolated nervous system, a direct link between light influences and motor patterns is still ambiguous.

Similarly, olfactory and mechanosensory pathways have been shown to exert longterm effects on the STNS motor circuits. In situ, a modulatory projection neuron, modulatory commissural neuron 1 (MCN1) is activated via chemosensory stimulation of the antennae. Stimulation and lesioning of MCN1 has long-term effects on the firing frequency and cycle period of the gastric mill and pyloric rhythms, two rhythmically active digestive behaviors (Hedrich et al., 2011).

In general, the extent to which hormonal and sensory influences interact and alter the long-term activity of motor circuits in intact animals remains unclear. On the behavioral side there is a lot of evidence for long-term modulation of rhythmic behaviors. For example, most animals experience a circadian pattern of locomotion activity, which is usually consistent 
with when they forage. This means that an innate daily pattern of activity exists that persist regardless of the environment conditions (Hardin and Panda, 2013). As circadian rhythms, light cycles can cause changes in activity. Yet, while light cycles can entrain circadian rhythms to keep them on a steady cycle period, they are not necessary to produce circadian rhythms. This has been previously shown in both invertebrates and vertebrates (Shlomo et al., 2002). Drosophila in particular has been used as a model system for studying circadian rhythms. The clock network responsible for circadian activity, the involved hormones and the genetic basis of circadian rhythmicity have been identified (Hermann et al., 2012; Stanewsky, 2003). However, changes in activity of individual neurons and networks in response to daily fluctuations have not been well-characterized, primarily because electrophysiological recordings are difficult in this system (Allen and Godenschwege, 2010).

To study long-term influences on rhythmic motor patterns, we are using long-term in vivo recordings of the gastric mill and pyloric motor patterns in the crab stomatogastric nervous system (STNS; Stein, 2009). The crustacean STNS is ideal for these kinds of studies since its motor patterns can be easily recorded from motor nerves and neurons in intact animals and in vitro, respectively. The pyloric rhythm is a triphasic rhythm that is constantly active and controls the filtration of food in the crab foregut. Its cycle period is between 0.5 and 2 seconds. The gastric mill rhythm is a much slower two-phase rhythm that controls the grinding of food within the gut. Its cycle period varies between 5 and 20 seconds. All circuit neurons, plus their synaptic connections in both CPGs have been identified (Marder and Bucher, 2007; Stein, 2009). The two rhythms are generated by two distinct, but overlapping sets of neurons in the stomatogastric ganglion (STG, Fig. 1). 
As a consequence, the pyloric rhythm can be influenced by intercircuit interactions with the gastric mill rhythm (Bartos and Nusbaum, 1997).

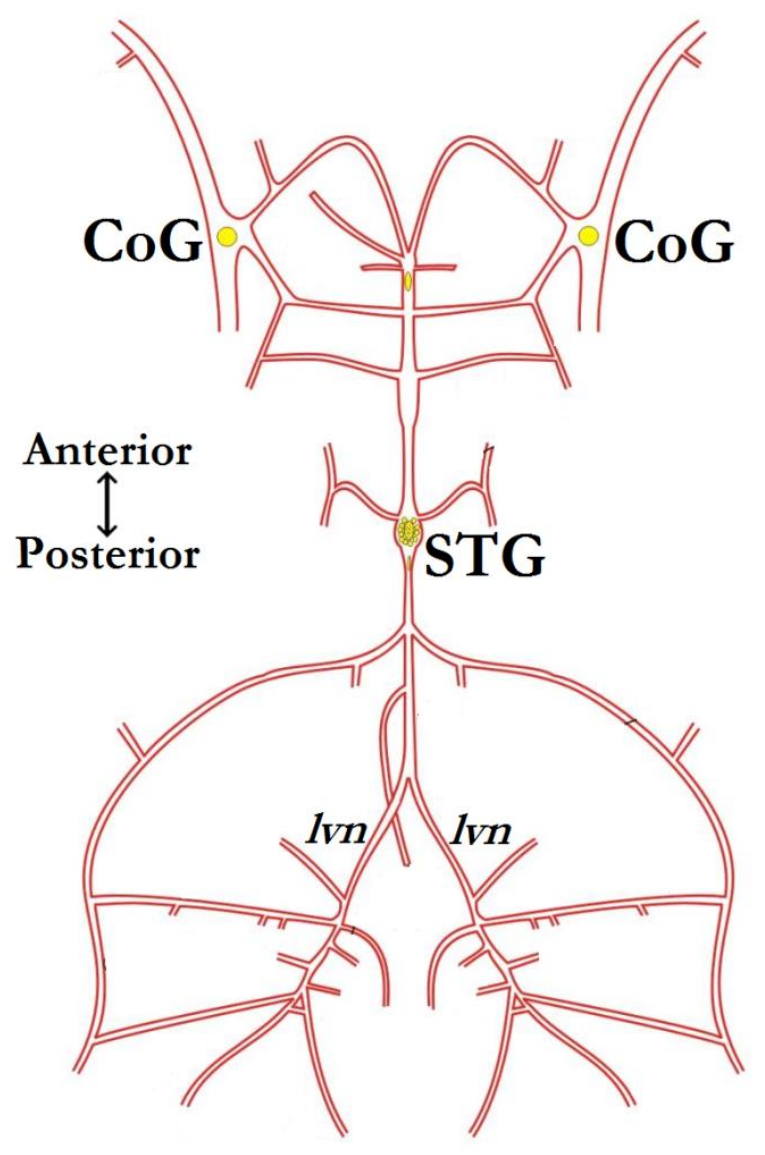

Figure 1: Diagram showing the crab stomatogastric nervous system.

Commissural ganglia (CoGs) contain projection neurons which innervate the neurons in the stomatogastric ganglion (STG) neurons. The extracellular activity patterns of the STG neurons are recorded via the lateral ventricular nerves (lvns).

The activity of both rhythms can be determined using extracellular recordings from the lateral ventricular nerve ( $l v n$, Fig. 1), which contains the axons of some of the neurons involved in these rhythms. The pyloric rhythm is characterized by a repeating 
sequence of activity from the LP (lateral pyloric), PY (pyloric constrictor), and PD (pyloric dilator) neurons (Fig. 2)

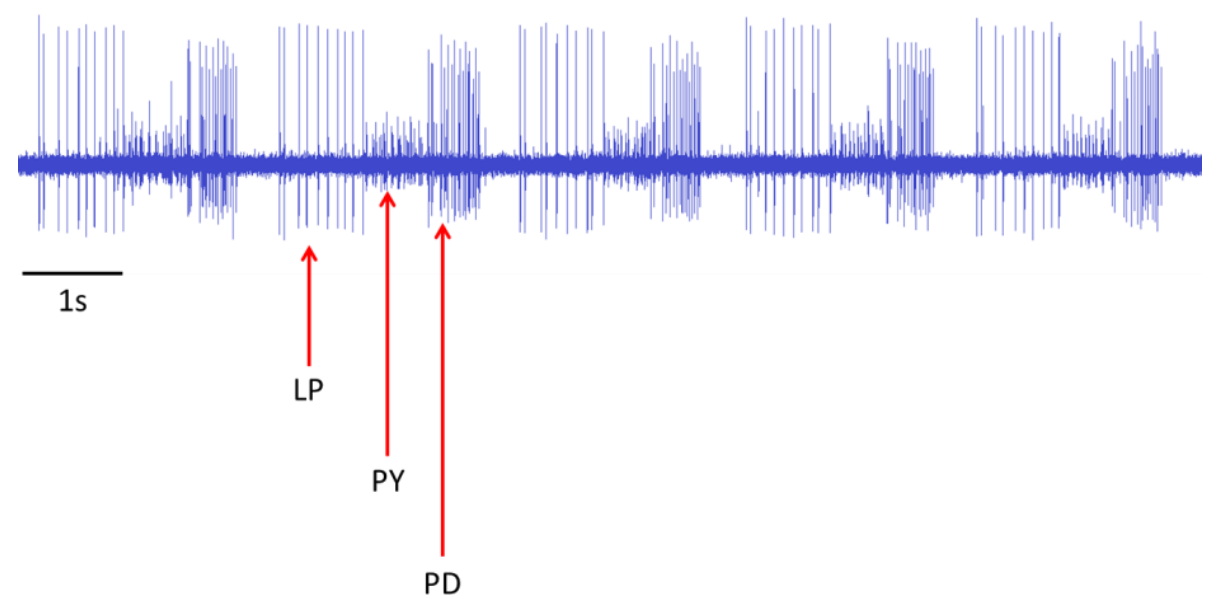

Figure 2: Example in vivo extracellular recording of the $l v n$ showing the pyloric rhythm.

The pyloric circuit contains a set of pacemaker neurons that drive its rhythmic output: the $\mathrm{AB}$ (anterior burster) neuron is a conditional pacemaker neuron and connected via gap junctions to two PD neurons. This group acts as the timer for the pyloric rhythm (Marder and Calabrese, 1996).

In contrast to the pyloric rhythm, the gastric mill rhythm is episodic and only activated in certain neuromodulatory conditions (Nusbaum and Beenhakker, 2002). The gastric mill circuit does not contain pacemaker neurons, but is rather driven by the reciprocal synaptic interactions between the lateral gastric (LG) neuron and Interneuron 1 (Stein et al., 2007). In order to initiate the rhythm, modulatory projection neurons such as MCN1 must be active to excite the gastric mill neurons (Bartos and Nusbaum, 1997). These projection neurons control the activity of the gastric mill rhythm and are located in 
the CoGs and thus extrinsic to the STG CPGs. The bursts of LG can be recorded on the lvn (Fig. 3), and indicate the presence and frequency of the gastric mill rhythm.

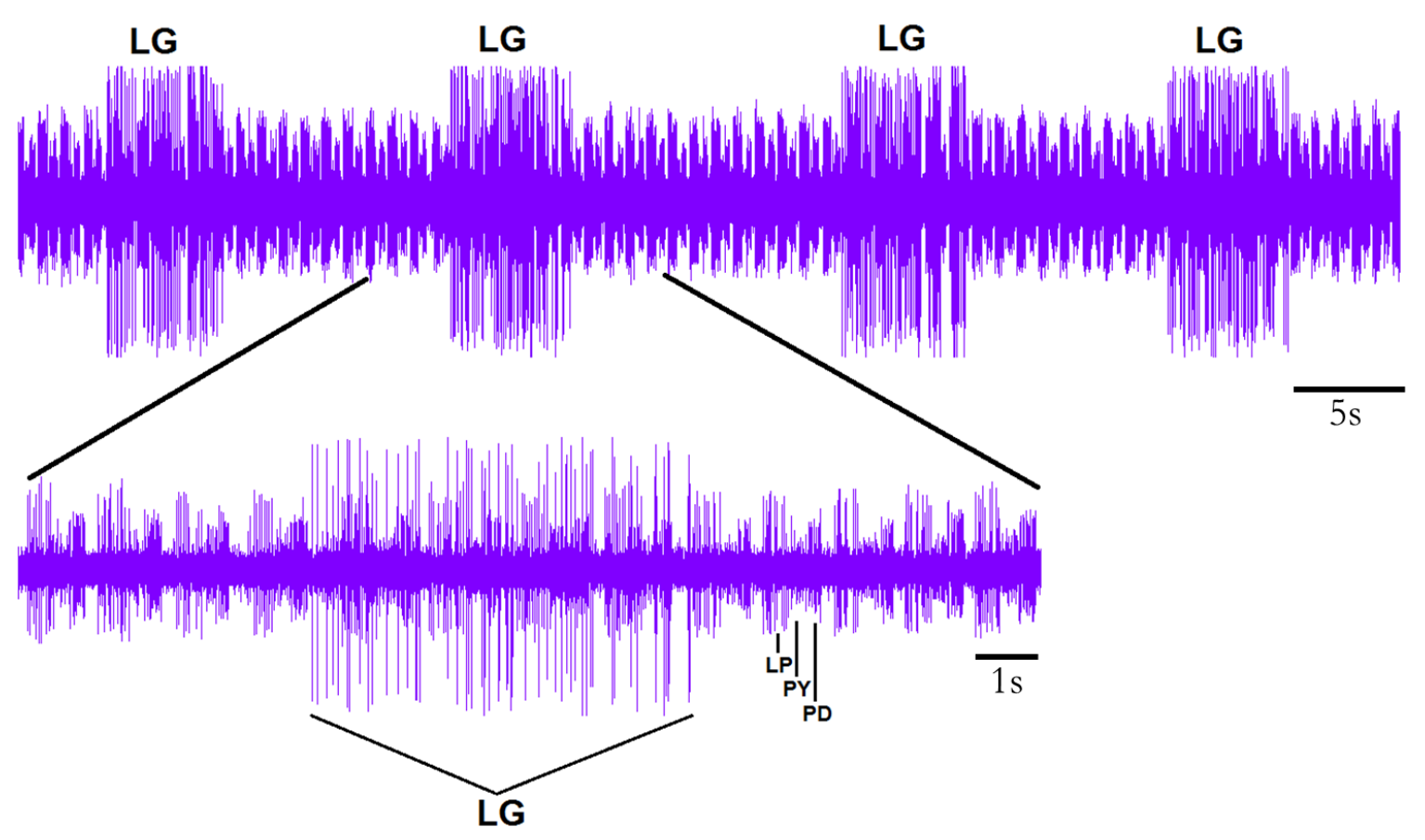

Figure 3: Example in vivo extracellular recording of the $l v n$ showing pyloric and gastric mill rhythms.

The pyloric rhythm has been particularly well characterized in vitro. Its canonical in vitro activity is similar to that in vivo (Hedrich et al., 2011). This is surprising since the activity of the pyloric motor neurons and their patterning are modulated by a variety of different neuromodulators (Li et al., 2002) and many of these modulators are present in the hemolymph (Chen et al., 2009). In addition, both the pyloric and gastric mill rhythms are continuously influenced by descending neuromodulatory pathways such as the earlier described projection neurons located in the CoGs (Nusbaum and Beenhakker, 2002). In vivo, hormones in the blood stream and environmental changes may also influence the rhythms. A 
large number of neuromodulators has been shown to be present in the STNS (Fig. 4) and their short-term actions on the pyloric rhythm as well as network and cellular targets have been determined in vitro (Stein, 2009). In vitro allatostatin application, for example, decreases the frequency of the pyloric rhythm in a dose dependent fashion (Skiebe and Schneider, 1994), while orcokinin application causes the number of LP neuron spikes per burst to decrease, and alters the phase of firing of the pyloric neurons (LI et al., 2002).

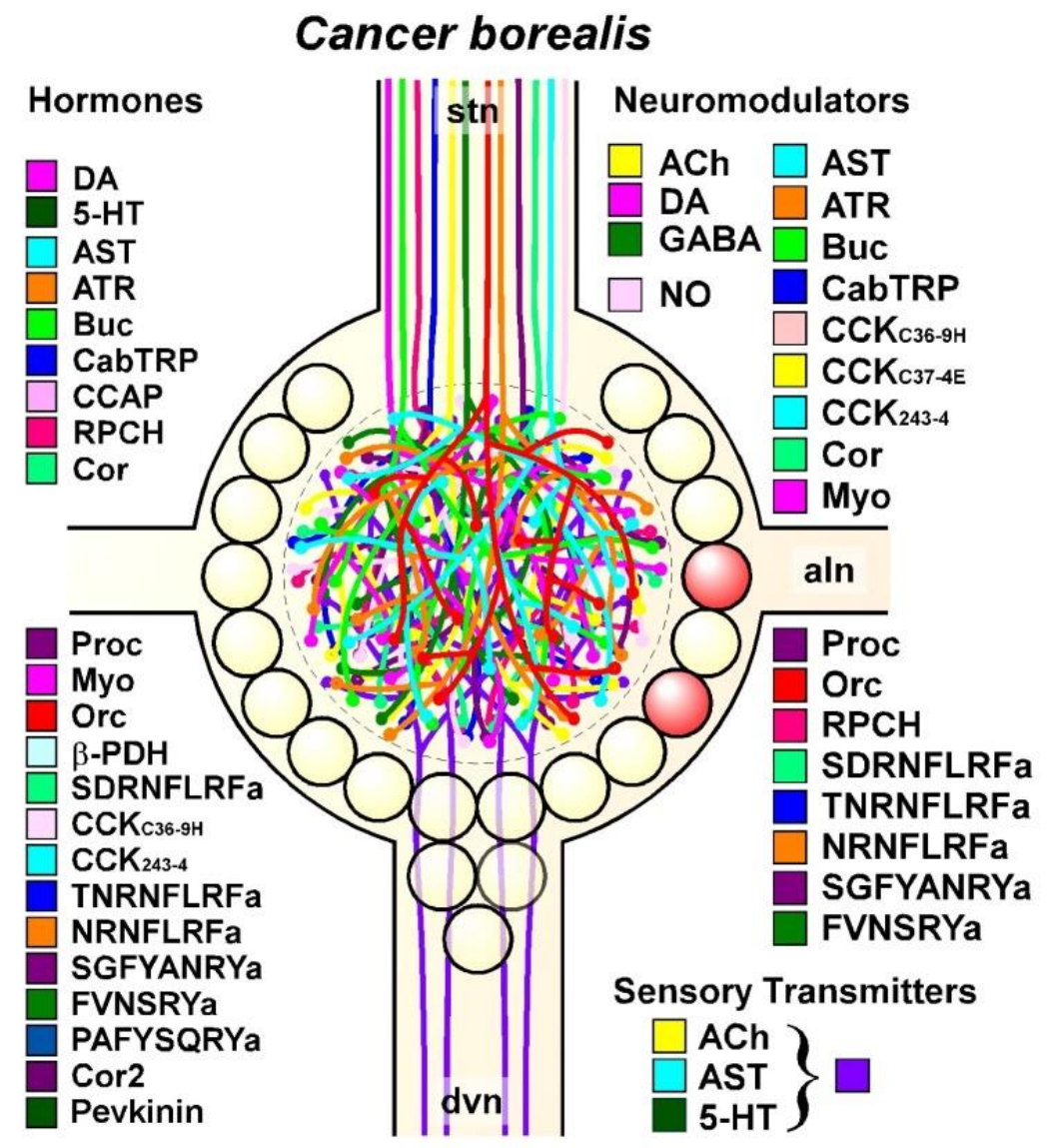

Figure 4: Modulators affecting the stomatogastric ganglion (STG).

This includes circulating hormones and neuromodulators which are delivered both locally and through descending modulatory projection neurons via the stomatogastric nerve $(s t n)$. Circles 
represent neurons, including LP, PY, PD, and LG all of which have axons which project through the dorsal ventricular nerve $(d v n)$ to the $l v n$ (Eve Marder website, http://blogs.brandeis.edu/marderlab/files/2012/01/modulatorsCancer.jpg, May 23, 2014).

However, while the origins of hormones and neuromodulators have been identified the neurohormonal pericardial organs (Marder and Bucher, 2007) and the previously mentioned descending modulatory projection neurons (Nusbaum and Beenhakker, 2002) - the influence of these modulators on the in vivo activity of the pyloric and gastric mill rhythms is mostly unknown. There is nothing known about the long-term (over multiple days) environmental influences on these rhythms. Correspondingly, the intrinsic range of variation of the rhythm as well as the range under various external and internal influences in vivo are, with few exceptions, unclear (Heinzel, 1993; Hedrich et al., 2011; Diehl et al., 2013; Soofi et al., 2014).

Rhythmic patterns of hormone release, as well as certain behaviors including locomotion, reproduction and molting have been studied in several species of crustaceans (although the motor circuits responsible for producing these behaviors were not identified (Strauss and Dircksen, 2010)). The studied species, the green crab, Carcinus maenas, and the fiddler crab, Uca pugnax, display a circatidal behavioral rhythmicity (Lynch and Rochette, 2007), foraging primarily during high tide. It is advantageous for these animals to sync their behavior with the tides in order to avoid predation, as they are more exposed when foraging at low tide.

A close relative, the rock crab was shown to have a 24 hour rhythm of locomotion with greater activity during the night and the highest peaks at dawn and dusk under 12 hours 
light, 12 hours dark conditions. Under total dark conditions, it shows a tidal rhythmicity (24.8 hour period) and under constant light, it shows little locomotion throughout the day (Rebach, 1985).

In regard to the Jonah crab, the species used in this study, one study suggested a diurnal pattern of activity. However this result was quantified by a count of visible animals, which does not exclude visible non-locomoting individuals (Novak, 2004) or environmental influences. No information on whether the Jonah crab's circadian rhythmicity persists in the lab, isolated from environmental stimuli is available. It is additionally important to know if an innate rhythm exists for this species in particular because so many general principles of neuromodulation and circuit interactions have been discovered using its nervous system. If a circadian rhythmicity exists at the neuronal level it may persist in vitro, which is important to consider when neural activity responses could be altered by the time of day an experiment is performed.

Locomotion is highly dependent on foraging behavior so digestive behavior should follow the same pattern of activity. Indeed, it is entirely possible that feeding is the actual underlying driver for locomotion. Therefore it is pertinent that the long-term digestive behavior of an animal also be considered when looking at what environmental cues are most important for determining the locomotor output of an animal. Food is also a practical cue for studying mechanisms of overriding innate circadian rhythms. This is because if an animal has just fed, there is no need for it to continue to forage, and is better suited to refocus its efforts on digestion, thus producing a different motor output. 
Animals are continuously exposed to both predictable (circadian) and random (food) variations in sensory stimuli, so they must be able to maintain a pattern of activity, which matches continuous patterns of variation in the environment as well as be able to quickly adapt to inconsistent changes. I hypothesize that long-term influences such as circadian rhythms as well as short-term feedback and motivation interact in vivo to modulate motor patterns and behavior.

\section{Sub-Objectives}

The purpose of this study is to determine (I) the long-term locomotor activity patterns of the crab, Cancer borealis, (II) the long-term in vivo activity patterns of the pyloric and gastric mill motor patterns, their correlation with sensory input, and their intercircuit interactions, and (III) the short-term sensory influences capable of overriding daily patterns of rhythmicity. The proposed study will mainly focus on the influence of light and food on motor pattern modulation. To determine if the gastric mill and pyloric rhythms are influenced by daily cues, experiments were performed in intact animals. The daily cue I controlled was the light cycle. To determine first whether both motor patterns are influenced either by circadian clocks or by the presence of ambient light, I characterized different aspects of the pyloric and gastric mill rhythms, including their frequencies and also the responses of individual neurons. For the pyloric rhythm, I looked at what proportion of the cycle period the neurons are active (their 'phase' of activity) and for the gastric mill rhythm characterized the occurrence of LG bursts, as the gastric mill is not always active. All parameters were characterized by their changes over time using long-term nerve recordings. If the gastric mill and pyloric rhythms are influenced 
by a circadian clock then their measured activity should (1) change with the time of the day and (2) be independent of the light cycle and persist under constant darkness.

Alternatively, if the rhythms are light driven, under constant darkness no daily changes in pyloric and gastric mill activities should be detectable. Further, in the case of lightdriven rhythms, pyloric and gastric mill activities under constant darkness should differ from that under constant light. Consequently, a comparison of activities between constant darkness and constant light enable the assessment of whether light influences the two motor patterns, and if so, what those influences are. Lastly, I expect that introducing a non-rhythmic cue (food) will override any periodicity observed over several days with only light as a sensory signal. Feeding will result in a different motor output that will overshadow the normal daily activity pattern 


\section{CHAPTER II}

\section{METHODS}

\section{Dissection}

I performed long-term in vivo motor pattern recordings from the lvn (similar to soofi et al., 2014). The first step of the dissection was to anesthetize the crab on ice for 30-50 minutes and cut open the dorsal side of the carapace (Fig. 5). I then located the lvn (Figure $5 \mathrm{~A}$, inset) and attached a small tube to the carapace with one end directly pointing at the $l v n$. I then inserted a wire (extracellular electrode) with a hooked end into the tube and carefully placed the $l v n$ onto the hook. I then pulled the nerve up to just inside the tube in order to electrically insulate it. I secured the wire to the tube using beeswax and filled the tube with "fast set" silicone to insulate the electrode from outside noise. Finally, I sealed the opening in the carapace using dental cement (Protemp ${ }^{\mathrm{TM}}$ Plus temporized material, Neuss, Germany) and Parafilm $^{\mathrm{TM}}$ (Figure. 5B), connected the electrode with an amplifier and returned the crab to its tank. 

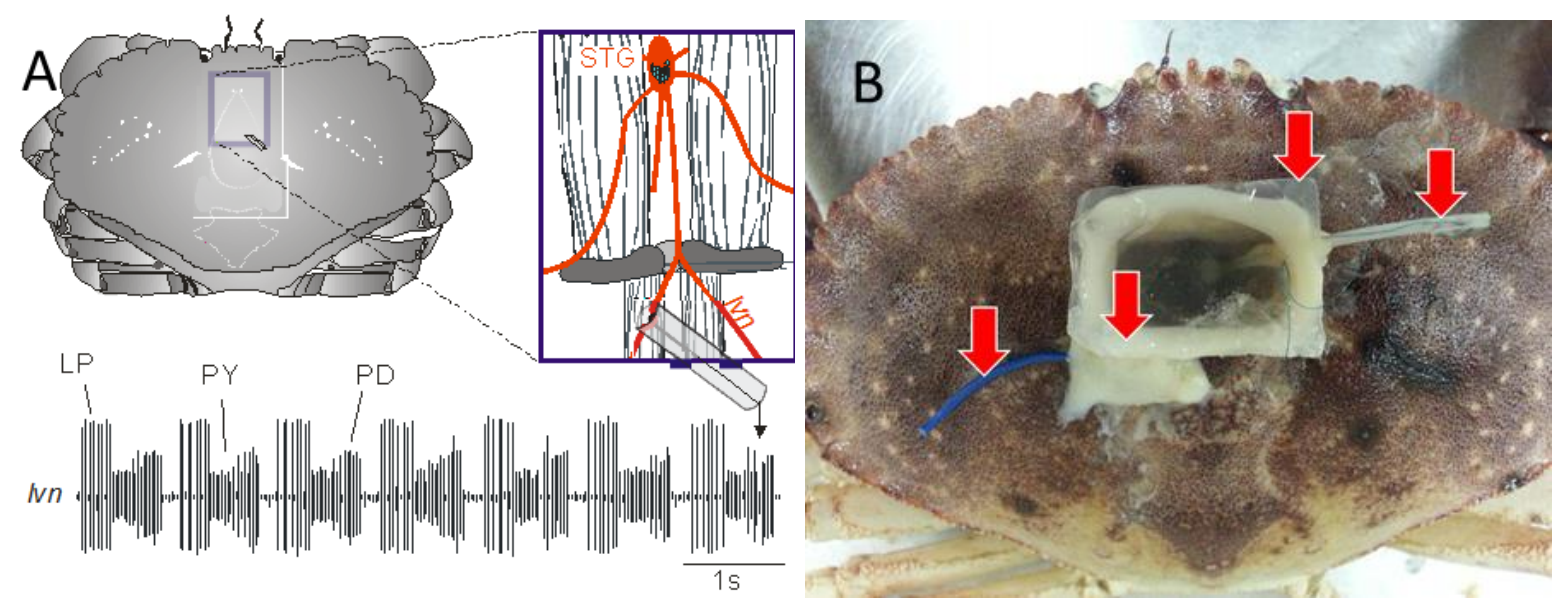

Figure 5: Extracellular in vivo recording setup.

Top: the dorsal the part of the carapace and hypodermis surrounded by the box on the diagram of the crab (left) was cut away, revealing the major afferent nerves of the stomatogastric nervous system and the gastric mill muscles (right). A single hook electrode was anchored around the lateral ventricular nerve $(l v n)$, and the nerve and hook were gently pulled into a tube filled with "fast set" silicone to insulate the contact point between the nerve and electrode from the surrounding hemolymph. The signal from $l v n$ was then recorded (bottom). Modified from Soofie et al., 2014. B) Dorsal view of completed in vivo surgery. Arrows left to right indicate wire connecting extracellular electrode to amplifier, dental cement, Parafilm ${ }^{\mathrm{TM}}$, and recording tubing with green wire (extracellular electrode) inside.

I also performed leg muscle recordings where I inserted an electrode into the muscle of the left posterior leg, secured the recording wire with dental cement (Protemp ${ }^{\mathrm{TM}}$ Plus temporized material, Neuss, Germany) and returned the animal to its tank. Locomotion was quantified by measuring the number of action potentials from the extensor muscle in the merus of the hindmost left leg per half hour (Fig. 6) (Bévengut and Cournil, 1990). 


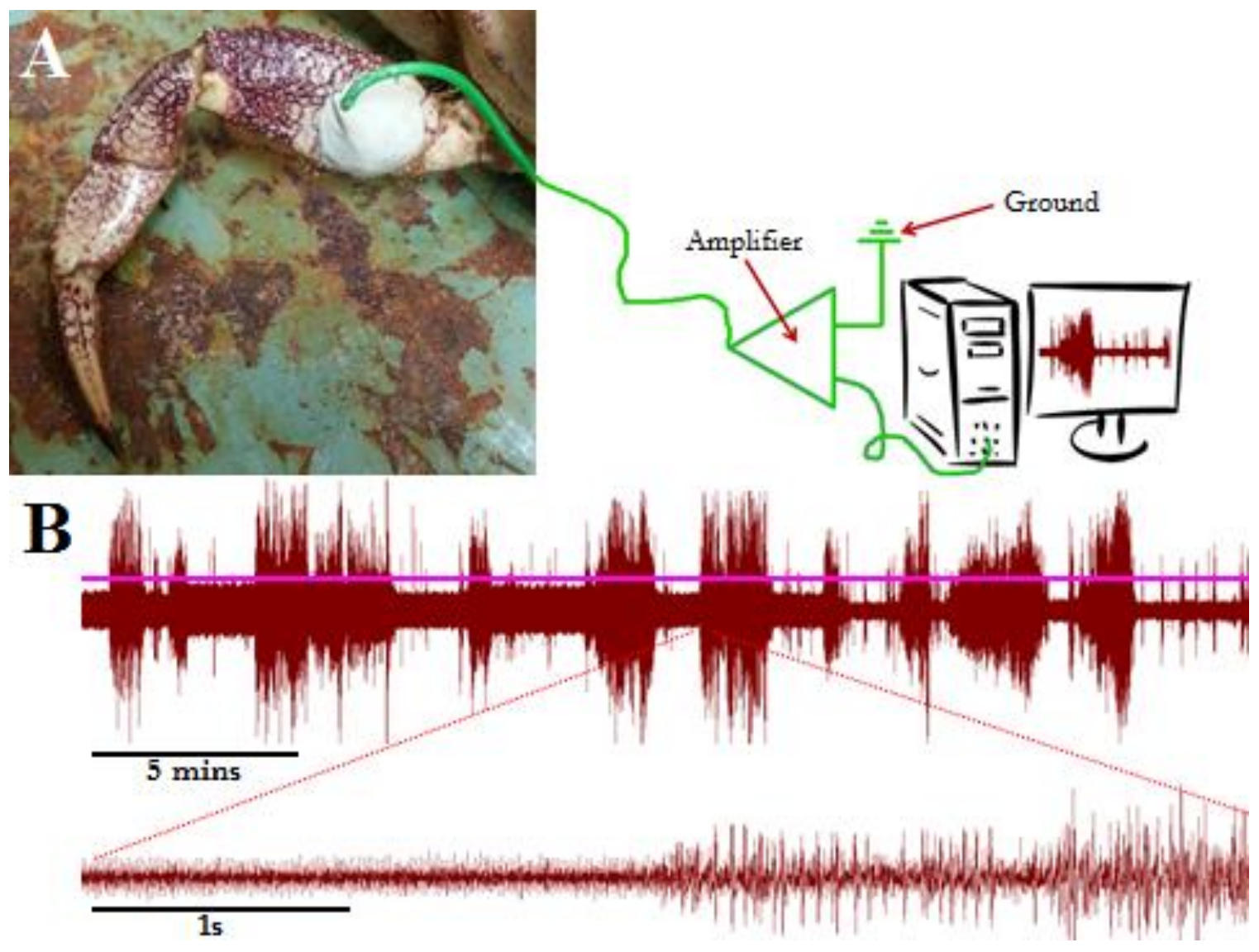

Figure 6: In vivo leg recording setup.

A) Recording wire inserted into merus of the left hindmost leg. B) Example muscle recording with pink threshold line showing minimum action potential amplitude counted.

\section{Light Cycle Experiments}

I collected long-term recordings under different light cycles including 12 hours light/12 hours dark (LD), 24 hours dark (DD), and 24 hours light (LL). The wavelengths, which composed the white light used, were within the visible range for crustaceans. Under the LD light cycle, I expected to find some daily changes in activity. The reason the other 
two cycles were selected was because if an innate rhythm is present, any daily activity pattern will persist under constant darkness. If the light cycle were responsible for a day/night shift in activity, a difference in activity would be evident when comparing constant darkness to constant light cycles.

Extracellular nerve activity was recorded, filtered and amplified through an amplifier from AM Systems (Model 1700, Carlsborg, WA, USA). Data were recorded onto a computer using Spike2 (CED) and a micro 1401 AD board (CED, Cambridge, UK). Data were analyzed using the Spike2 script language to determine the frequency of the pyloric and gastric mill rhythms, the activity patterns of their motor neurons and the occurrence of action potentials in the left posterior leg.

\section{Sensory Manipulations}

Since the motor patterns recorded drive processing of food, I analyzed of the effect of feeding and the effect of the presence of food without ingestion on the pyloric and gastric mill rhythms. Because all the tanks where the crabs are housed share the same water, when food was placed in other tanks it served as an olfactory cue without actual feeding. This served as a control and indicated if these sensory stimuli were a cause of motor activity that may dampen circadian or light-driven influences. Because feeding has a long lasting effect on these circuits, each animal's neural activity was analyzed for the 6 hours before and 6 hours after feeding. Additionally, some experiments were performed on animals isolated from the other tanks in order to ensure that observed variability of activity was not a side effect of the shared water environment. 


\section{Statistical Analysis}

I used SAS statistical software to perform either a repeated measures ANOVA or generalized linear mixed model to compare different times of day including, day, night, dawn, dusk, midday, and midnight. For testing differences between two conditions, a ttest was used in case of normal distribution, and a Wilcoxon signed rank test when data were not normally distributed. For example, the effect of the gastric mill rhythm on pyloric cycle frequency was tested using a Wilcoxon signed rank test, as there are clear control and test conditions (before and during gastric mill rhythm), but no clear post control due to the slow and discontinuous disappearance of the gastric mill rhythm. For correlations, a Pearson's product-moment correlation was used for parametric data and a Spearman rank-order correlation was used for non-parametric data. 


\section{CHAPTER III}

\section{RESULTS}

\section{No Consistent Daily Rhythmicity Exists for Locomotion}

It is currently unclear whether $C$. borealis shows a daily pattern of locomotion. Novak (2004) suggested a diurnal circadian rhythm, but in this study only the number of visible animals at different times of the day was measured. No quantification of actual movement was performed in this field study and it remains unclear whether the observed diurnal rhythm was innate or environmentally driven. In order to characterize the longterm locomotor activity of the Jonah crab I performed a lab study in which leg muscles in freely behaving animals were recorded. Locomotion was quantified by measuring the number of action potentials from the extensor muscle in the merus of the hindmost left leg per half hour (Fig. 6: Methods) (Bévengut and Cournil, 1990). Data were recorded for 4 days in 12 hrs. light/ 12 hrs. dark (LD) conditions followed by 2 days in 24 hrs. dark (DD) conditions. The results were highly variable between individuals. In total $\mathrm{N}=5$ animals were tested. Animals either exhibited crepuscular (Fig. 7 Top left), diurnal (Fig. 7 Middle left) or seemingly random patterns of activity (Fig. 7 bottom left). To determine whether the observed individual patterns of locomotion were innate or light driven, the initial two days of LD conditions were followed by two days of DD conditions. The animal, which appeared to have a crepuscular activity pattern, was active for $\sim 7$ hours after every time the lights changed, but discontinued this pattern when the 
light was continuously off (Fig. 7 top). None of the individual animals' patterns of activity persisted under constant darkness (Fig. 7 top, middle, and bottom right) indicating that their rhythms were not innate and that they were more likely dependent on the light cycle or other sensory inputs than on an internal clock. The middle example in Figure 7 shows an animal that was consistently more active during the daytime when the lights were on, and this pattern even continued after the lights were turned off, but the animal was no longer consistently inactive during the night. The last example (Fig. 7 bottom) shows an animal with no pattern of activity with or without the light cue. This animal was moderately active during the first day, and then it was inactive for the next two and a half days, followed by a 5.5 hour bout of activity and finally returned to quiescence for the remainder of the recording time.

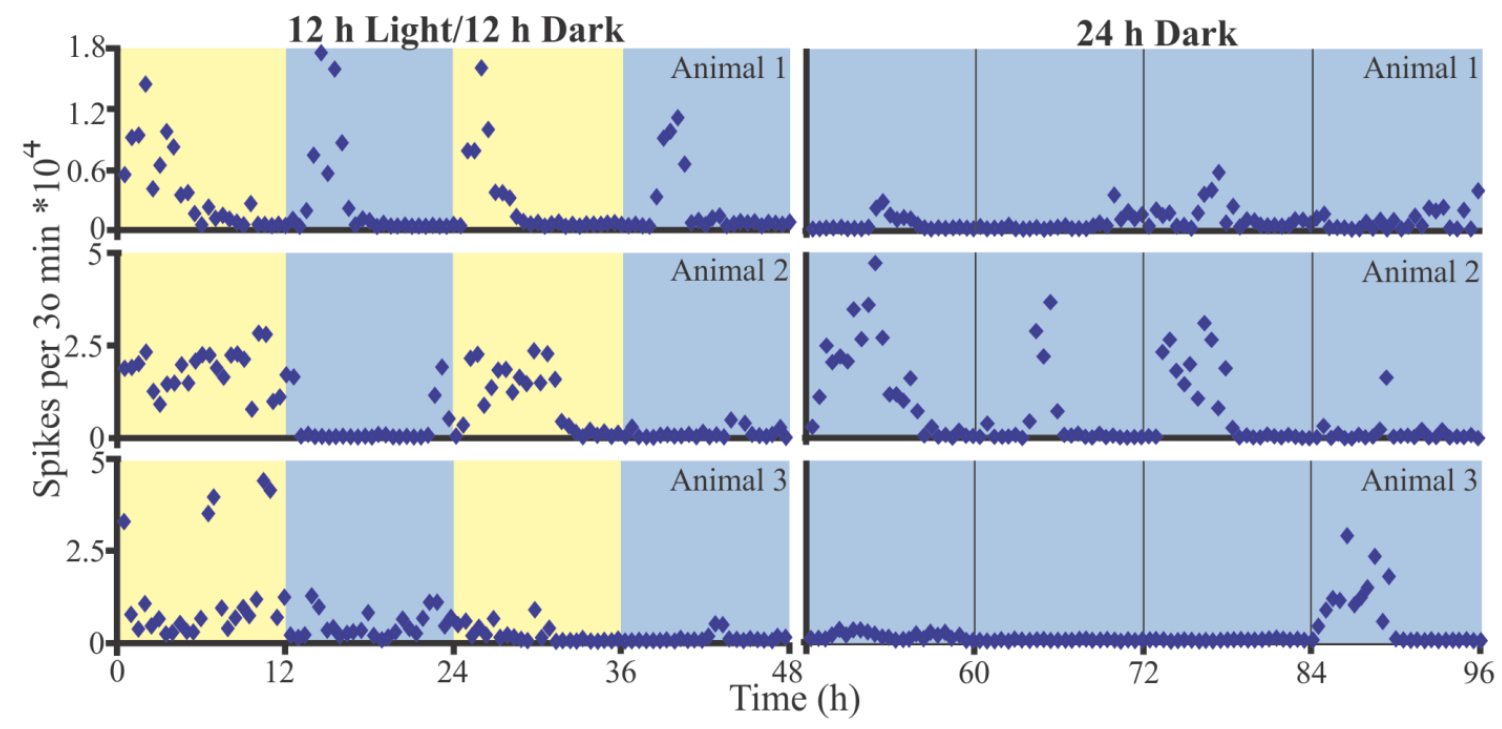

Figure 7: Example in vivo locomotor activity.

Figure shows three animals over 2 days under LD light cycle followed by 2 days under DD light cycle. Yellow area indicates light, blue indicates dark. Each data point 
represents a 30 minute bin containing the total number of action potentials for that time point.

Although there was no consistent daily movement pattern, this lack of a circadian locomotor rhythm did not exclude other motor systems from having daily patterns. Since it was suggested that Cancer borealis has a circadian rhythm in its "visibility" (Novak, 2004) and since they are opportunistic feeders, food processing in the foregut may have phases of higher and lower activity that correspond to its visibility rather than its locomotor activity. It may be that during times of visibility these animals are foraging and thus suppressing food processing whereas when they are not visible they are no longer actively seeking and consuming food and can refocus their energy on digestion. Therefore it is pertinent to explore the possibility of a circadian clock, which controls food processing.

\section{Pyloric and Gastric Mill Frequencies are Highly Variable, but with no Obvious Daily Pattern within Individuals}

Food processing in the foregut is driven by the pyloric and gastric mill rhythms (Harris-Warrick, 1992). The pyloric rhythm controls the muscles that dilate and constrict the pyloric region of the stomach, which acts as a filter for the food. The gastric mill rhythm controls the muscles which produce chewing behavior. In order to measure the long-term modulation of the pyloric and gastric mill rhythms I performed a minimally invasive surgery allowing the measurement of the motor output of the pyloric and gastric mill circuits in vivo. For this, I permanently implanted an extracellular hook electrode and recorded the activity of the LP, PY, PD, and LG neurons whose axons are located within 
the $l v n$. Using this technique, I was able to record stable motor patterns from the gastric mill and pyloric rhythms for as long as six weeks $(\mathrm{N}=27$ animals, median=5.25 days, mean=6.8). From these recordings I calculated the frequencies of the pyloric and gastric mill rhythms continuously over several days (Fig. 8) and used them as a measure for the activity of digestive behavior. Figure 7 shows a typical example of the variability of the pyloric frequency in vivo. The pyloric frequency is very unstable over long periods where it continuously oscillates up and down on a scale of minutes to hours and additionally on a longer scale of hours to days. Within individuals no obvious pattern to those continuous changes was observed.

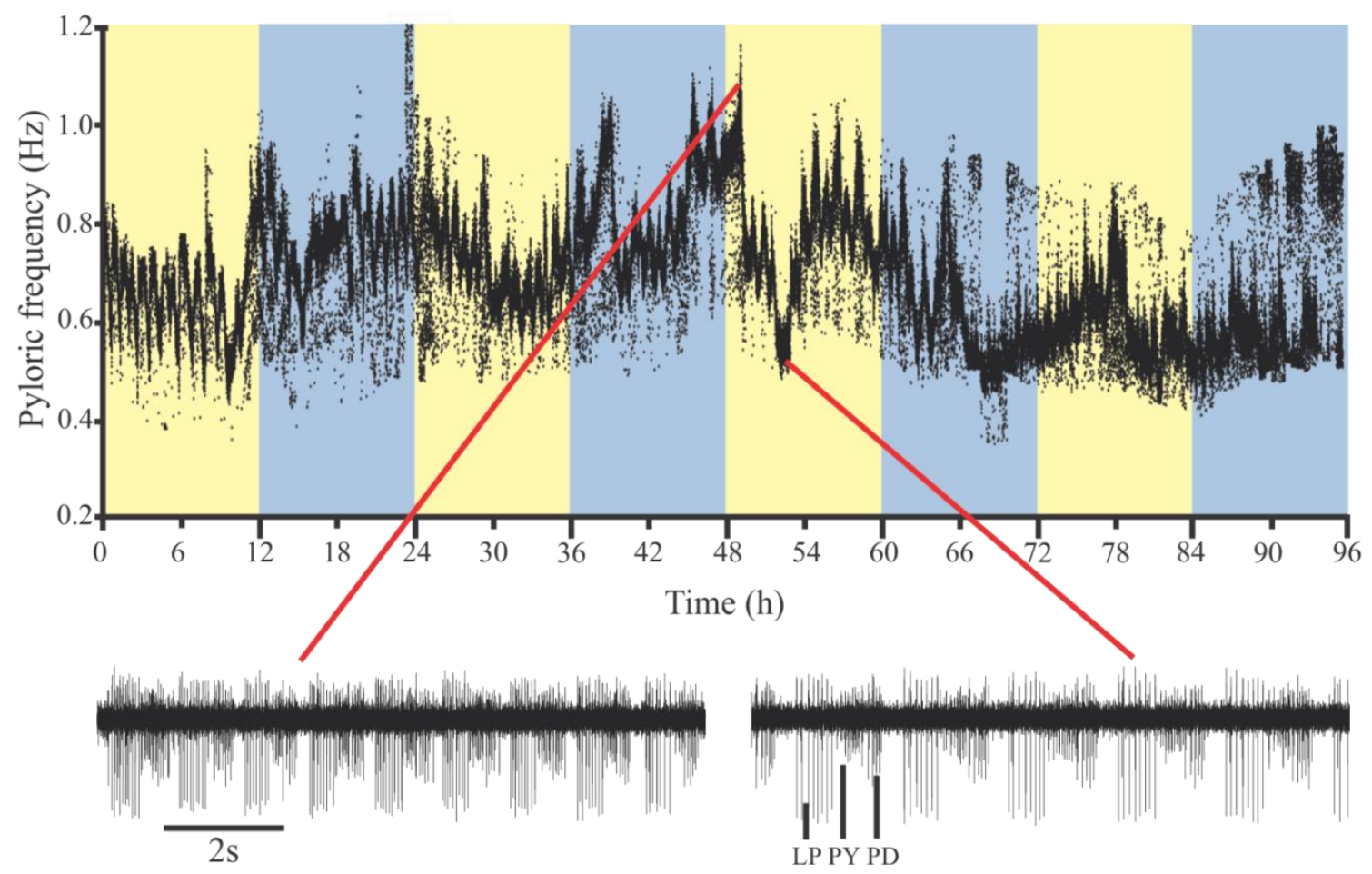

Figure 8: Example in vivo pyloric frequency. 
Figure shows pyloric frequency over 4 days under a LD light cycle in one animal. Yellow area indicates light, blue indicates dark. Each data point represents the frequency of one pyloric cycle. Lower traces show example pyloric rhythms with differing frequencies.

There is No Difference in Pyloric and Gastric Mill Frequencies between Day and Night

I compared the frequencies of the pyloric and gastric mill rhythms at different times of day under LD conditions. For each animal I averaged all cycle frequencies for the 12 hours during the day and the 12 hours during the night across three days of recordings. There were no significant differences between light and dark phases for either frequency in these conditions (Figs 9, 10, Table 1) (Pyloric: Paired t test $\mathrm{P}=0.535$, $\bar{y}=0.013+/-0.054, N=7$ animals; Gastric mill: Paired t test $P=0.113, \bar{y}=0.023+/-0.026$, $\mathrm{N}=5$ Animals). This indicated that no diurnal or nocturnal rhythm exists for the frequencies of these motor behaviors, so additional light manipulations were not explored.

Table 1: Pyloric and gastric mill frequency averages in $\mathrm{Hz}$ at different times of day.

\begin{tabular}{|c|c|c|c|c|}
\hline $\begin{array}{l}\text { Light condition/motor } \\
\text { rhythm }\end{array}$ & LD/Pyloric & DD/Pyloric & LL/Pyloric & LD/Gastric \\
\hline Day & $\begin{array}{l}0.652+/- \\
0.157\end{array}$ & $0.586+/-0.019$ & $\begin{array}{l}0.656+/- \\
0.027\end{array}$ & $0.042+/-0.020$ \\
\hline Night & $\begin{array}{l}0.666+/- \\
0.175\end{array}$ & $0.563+/-0.023$ & $\begin{array}{l}0.674+/- \\
0.030\end{array}$ & $0.041+/-0.017$ \\
\hline Dawn/Dusk & $\begin{array}{l}0.667+/- \\
0.160\end{array}$ & $0.576+/-0.026$ & $\begin{array}{l}0.663+/- \\
0.032\end{array}$ & $0.043+/-0.018$ \\
\hline Midday/Midnight & $\begin{array}{l}0.651+/- \\
0.168\end{array}$ & $0.573+/-0.025$ & $\begin{array}{l}0.667+/- \\
0.026\end{array}$ & $0.041+/-0.019$ \\
\hline
\end{tabular}




\section{There is an Increase in Pyloric and Gastric Mill Frequency during Dawn and Dusk}

There was a significant increase in the frequency of the pyloric and gastric mill rhythms during the 12 hours surrounding dawn and dusk, compared with the 12 hours surrounding midday and midnight under LD condition (Figs 9, 10) (Pyloric: repeated measures ANOVA $\mathrm{P}=0.021, \mathrm{~N}=7$ animals, $\mathrm{F}(7,12)=3.91$; Gastric mill repeated measures ANOVA $\mathrm{P}=0.010, \mathrm{~N}=4$ animals, $\mathrm{F}(3,6)=1.12)$. To determine whether there was a difference between the first and second 12 hours of the day under LD conditions, or if the same cycle of activity was just repeated twice in one day, I compared the frequency of both rhythms during the hours surrounding dawn to the hours surrounding dusk and also the hours surrounding midday to the hours surrounding midnight. If there were no difference, this would indicate a12 hour rhythmicity as opposed to 24 hours because if the first and second halves of the day were different it would take the full 24 hours to complete a full cycle. As it were, there was no difference in either rhythm's frequency between dawn and dusk (Figs 9, 10) (Pyloric: repeated measures ANOVA P=0.420, $\mathrm{F}(7,12)=3.91$; Gastric mill: Pyloric: repeated measures ANOVA $\mathrm{P}=0.242)$ or between midday and midnight (Figs 9, 10) (Pyloric: repeated measures ANOVA P=0.645; Gastric mill: repeated measures ANOVA $\mathrm{P}=0.663, \mathrm{~F}(3,6)=1.12)$. Thus, because the first and second halves of the day are identical, it shows that it only takes 12 hours for a cycle to be completed before repeating itself. However, after using a Bonferoni correction to adjust the accepted p-values for the three contrasts (day vs. night, dawn vs. dusk, and midday vs. midnight) performed, the difference between dawn/dusk and midday/midnight was no longer significant for the pyloric rhythm, as this made the cutoff 
$\mathrm{P}$ value 0.017 . Though, with a larger $\mathrm{N}$ it is likely that the difference would become significant once more.

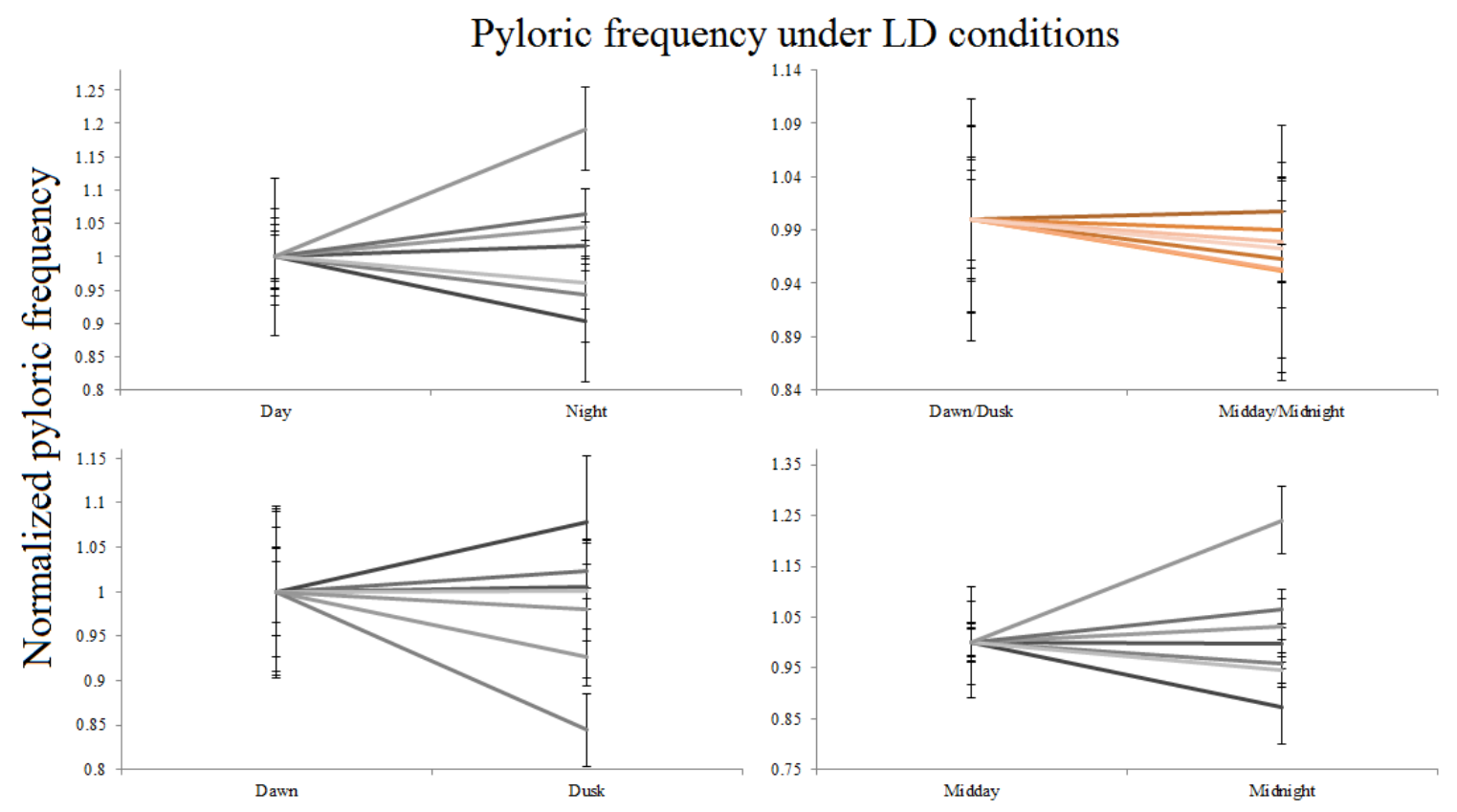

Figure 9: Normalized pyloric frequency at different times of day under LD conditions.

$\mathrm{N}=7$ animals. Orange figure indicates significance. Data were normalized to day, dawn/dusk, dawn, or midday respectively. 
Gastric mill frequency under LD conditions
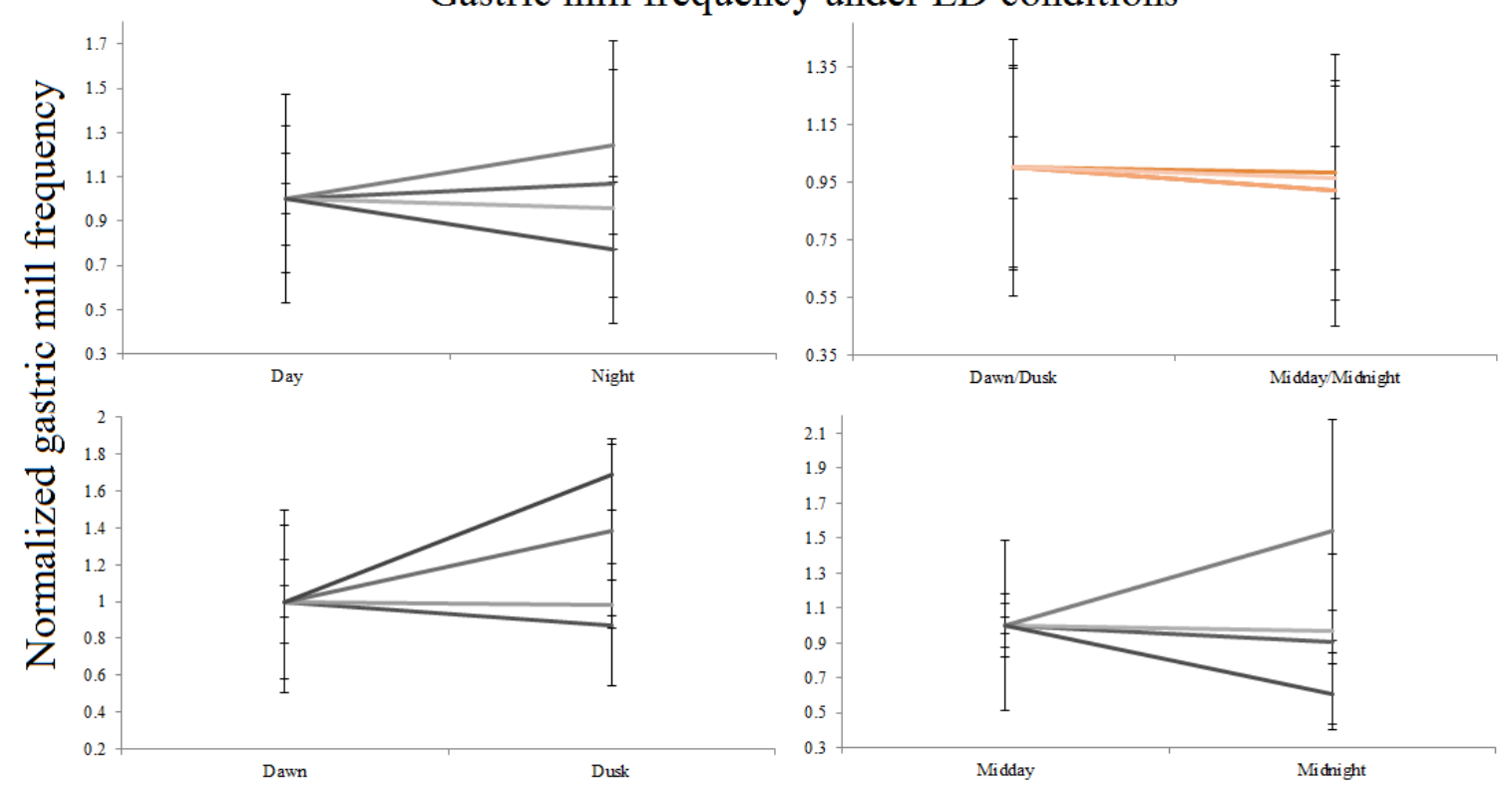

Figure 10: Normalized gastric mill frequency at different times of day under LD conditions.

$\mathrm{N}=4$ animals. Orange figure indicates significance. Data were normalized to day, dawn/dusk, dawn, or midday respectively.

\section{Increased Frequency during Dawn and Dusk does not Persist Under Constant Light \\ Conditions}

To determine whether the observed increase in frequency during dawn and under LD conditions was an innate or light driven cycle, I performed the same experiment under constant dark conditions. There was no significant difference in the pyloric frequency between day and night or between dawn/dusk and midday/midnight under constant dark conditions (Fig. 11) (Day vs. night: Paired t test $\mathrm{P}=0.113, \overline{\mathrm{y}}=0.023+/-0.026$; Dawn \& dusk vs. midday \& midnight: Paired t test $\mathrm{P}=0.636, \overline{\mathrm{y}}=0.004+-0.016, \mathrm{~N}=5$ 
Animals). This indicates that the frequency of the pyloric rhythm has no innate rhythmicity, but rather responds to the lights changing.
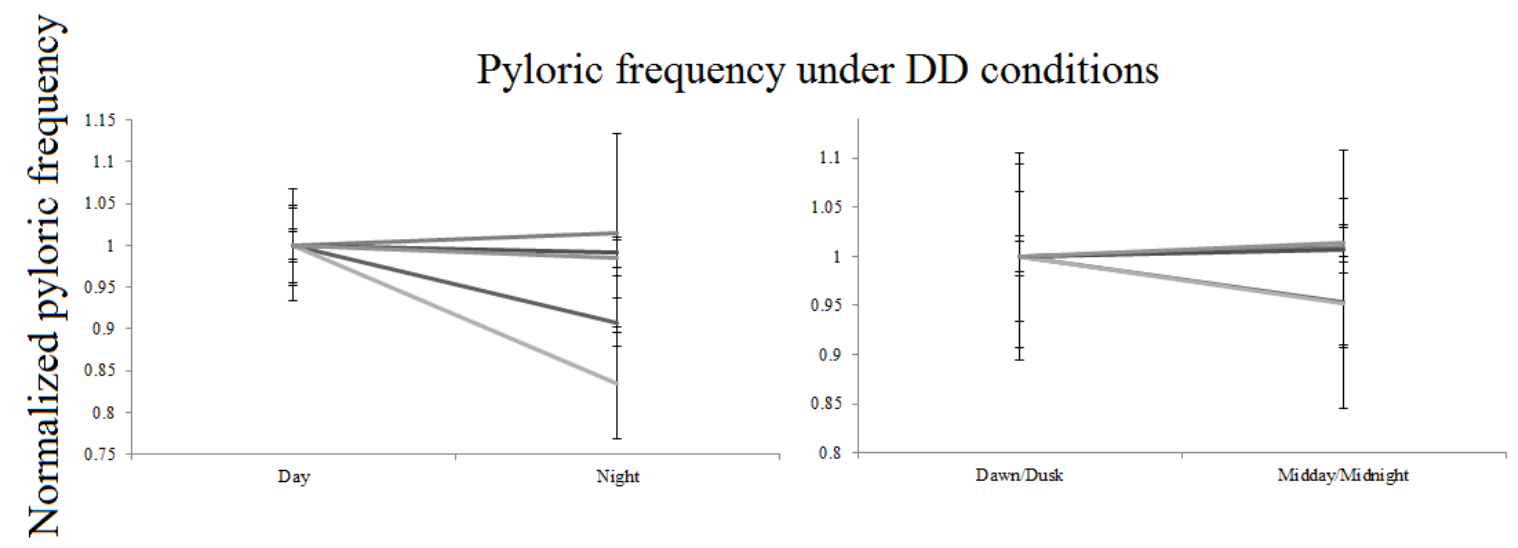

Figure 11: Pyloric frequency at different times of day under DD conditions.

$\mathrm{N}=5$ animals. There were no significant differences. Data were normalized to day, or dawn/dusk respectively.

Under constant light conditions, there was also no significant difference for either daytime versus night or dawn/dusk versus midday/midnight for the pyloric frequency (Fig. 12) (Day vs. night: Paired t test $\mathrm{P}=0.18, \overline{\mathrm{y}}=0.017+/-0.015$; Dawn \& dusk vs. midday \& midnight: Paired t test $\mathrm{P}=0.755, \overline{\mathrm{y}}=0.005+-0.023, \mathrm{~N}=3$ Animals). 


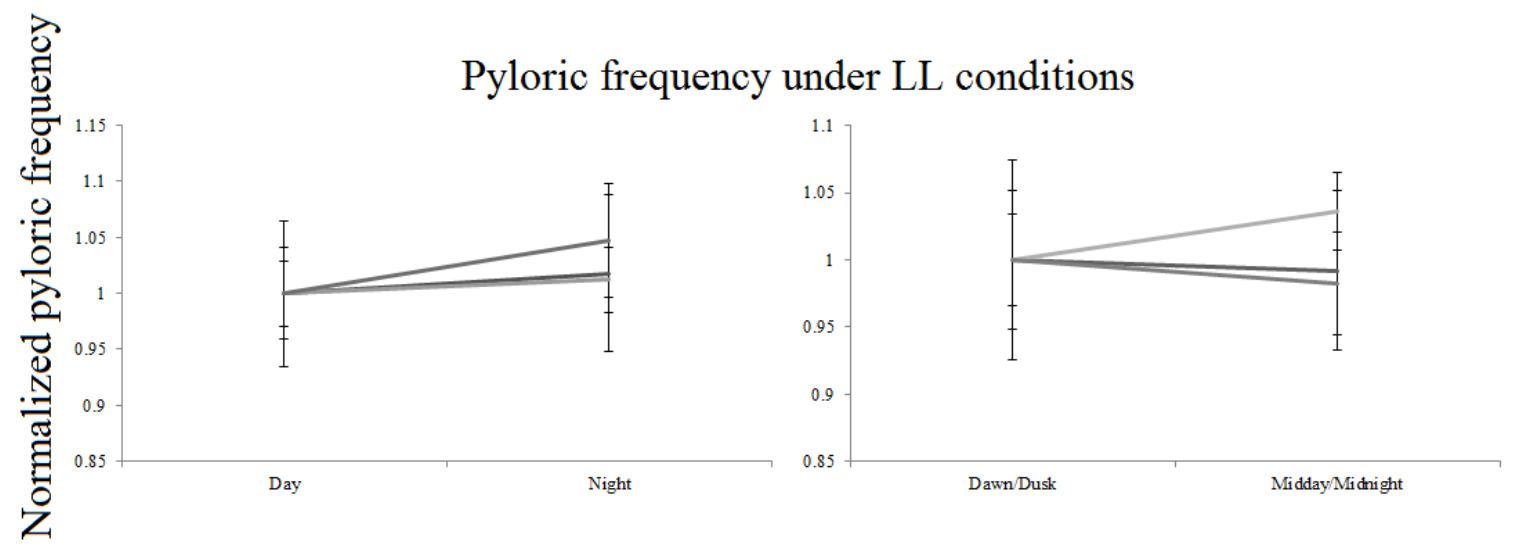

Figure 12: Pyloric frequency at different times of day under LL conditions.

$\mathrm{N}=3$ animals. There were no significant differences. Data were normalized to day, or dawn/dusk respectively.

A similar test for the gastric mill frequency could not be completed because there were too few recordings with quantifiable LG bursts.

\section{The Structure of the Pyloric Rhythm Remains Stable across Pyloric Frequencies}

Another important characteristic of the rhythmic motor patterns besides frequency is structure (Diehl et al., 2013). The variables I used to describe the structure of the pyloric rhythm included the intraburst spike frequency and intraburst spike duration of individual neurons as well as the percent of time a particular neuron was active during the pyloric cycle (the duty cycle). While frequency has previously been shown to vary substantially in response to temperature change, the duty cycles of the pyloric neurons tend to be much more stable in response to environmental variations (Soofi et al., 2014).

In vivo, it is impossible to separate the activity patterns of all pyloric neurons. This is due to the fact that only one recording of $l v n$ is possible and there are multiple 
units present in this nerve. Additionally there is a decreased signal to noise ratio in vivo compared with in vitro recordings. Consequently, the only pyloric neuron which allowed for structure analysis was LP (see also Soofi et al., 2014). A total of 4 animals were analyzed over three days to determine the stability and variability of the structure of the pyloric rhythm using different characteristics of LP activity.

The time of day had no effect on the duty cycle of LP. The duty cycle remained constant over very long-periods (Fig. 13). This was a result of the burst duration of LP being negatively correlated with the frequency of the pyloric rhythm. Longer bursts occurred with longer cycle periods thus maintaining the duty cycle. Similarly, the mean spike frequency was negatively correlated with the burst duration. In contrast, the mean spike frequency was positively correlated with the pyloric frequency indicating that intraburst spike frequency increased during faster rhythms (Table 2). All of these changes help to maintain the structure of the rhythm. When the rhythm speeds up, the burst duration decreases to maintain phasing and the spike frequency increases to maintain a similar number of spikes per burst. 

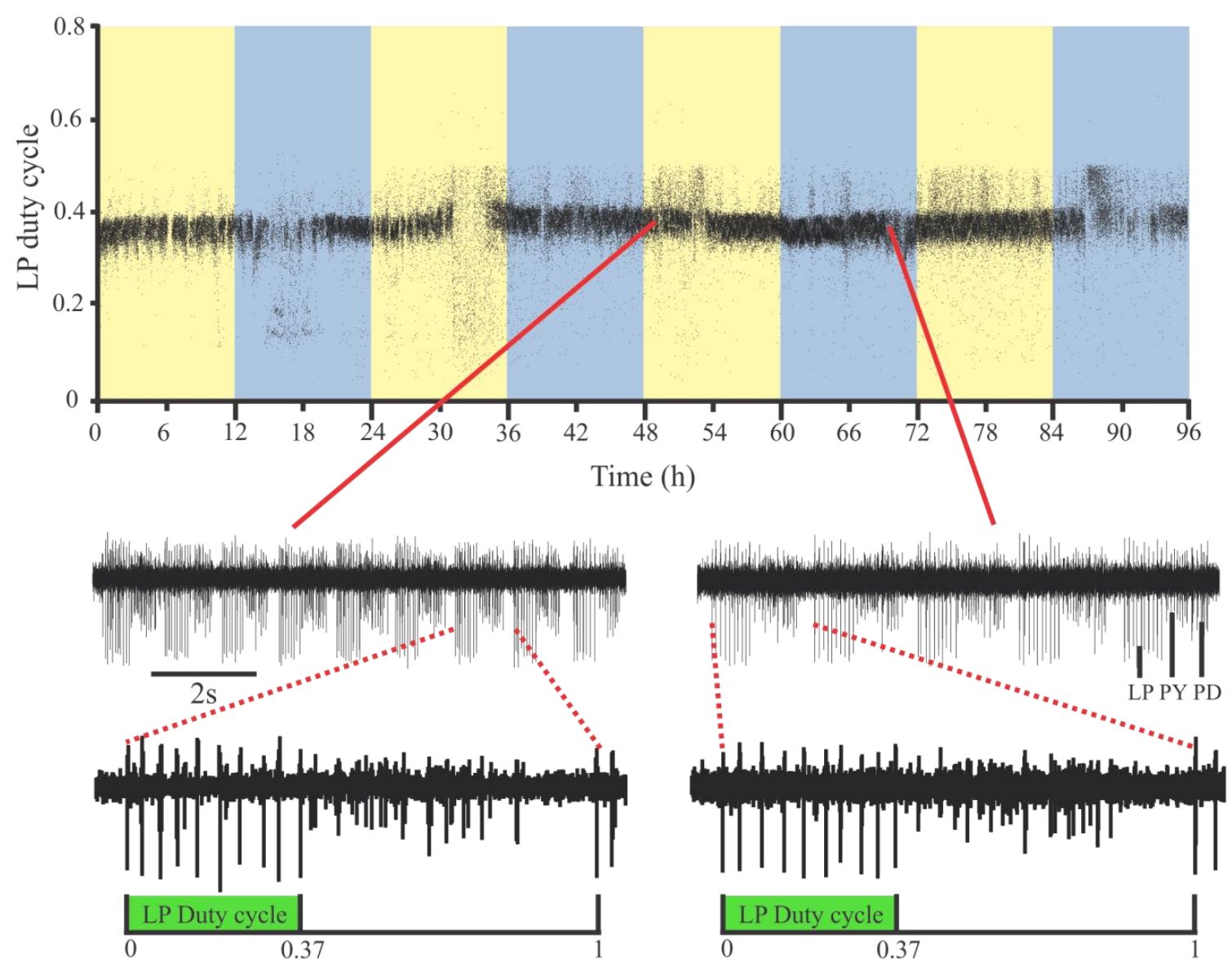

Figure 13: Example in vivo LP duty cycle.

Figure shows 4 days under a LD light cycle in one animal. Yellow area indicates light, blue indicates dark. Each data point represents the LP duty cycle of one pyloric cycle. Lower traces show example pyloric rhythms with differing frequencies, but equal duty cycles. 
Table 2: Summary statistics for burst structure of LP.

Spearman rank-order correlations were used to determine $\mathrm{P}$ and $\rho$. $\mathrm{P}$ values give significance $\rho$ values give the linear relationship between the two variables.

\begin{tabular}{|l|l|l|l|}
\hline Animal & $\begin{array}{l}\text { Pyloric frequency } \\
\text { vs. Burst duration }\end{array}$ & $\begin{array}{l}\text { Mean spike } \\
\text { frequency vs. } \\
\text { Pyloric frequency }\end{array}$ & $\begin{array}{l}\text { Mean spike } \\
\text { frequency vs. Burst } \\
\text { duration }\end{array}$ \\
\hline 1 & $\mathrm{P}<0.0001 \rho=-0.804$ & $\mathrm{P}<0.0001 \rho=0.753$ & $\mathrm{P}<0.0001 \rho=-0.416$ \\
\hline 2 & $\mathrm{P}<0.0001 \rho=-0.911$ & $\mathrm{P}<0.0001 \rho=0.876$ & $\mathrm{P}<0.0001 \rho=-0.755$ \\
\hline 3 & $\mathrm{P}<0.0001 \rho=-0.836$ & $\mathrm{P}<0.0001 \rho=0.925$ & $\mathrm{P}<0.0001 \rho=-0.662$ \\
\hline 4 & $\mathrm{P}<0.0001 \rho=-0.649$ & $\mathrm{P}<0.0001 \rho=0.897$ & $\mathrm{P}<0.0001 \rho=-0.580$ \\
\hline
\end{tabular}

\section{The Gastric Mill and Pyloric Frequencies are Highly Correlated}

Because the gastric mill and pyloric circuits have been shown to interact in vitro I wanted to determine if similar interactions existed in vivo (Bartos and Nusbaum, 1997). To determine if the activity of the two rhythms were dependent on one another I looked at their frequencies within individual animals. There was a clear correlation between the pyloric frequency and the gastric mill frequency regardless of the light condition (Fig. 14) in all tested animals $(\mathrm{N}=5)$. This correlation indicates that any long-term influences on the pyloric frequency will also be observed in the gastric mill frequency because both rhythms consistently change in synchrony with one another. 


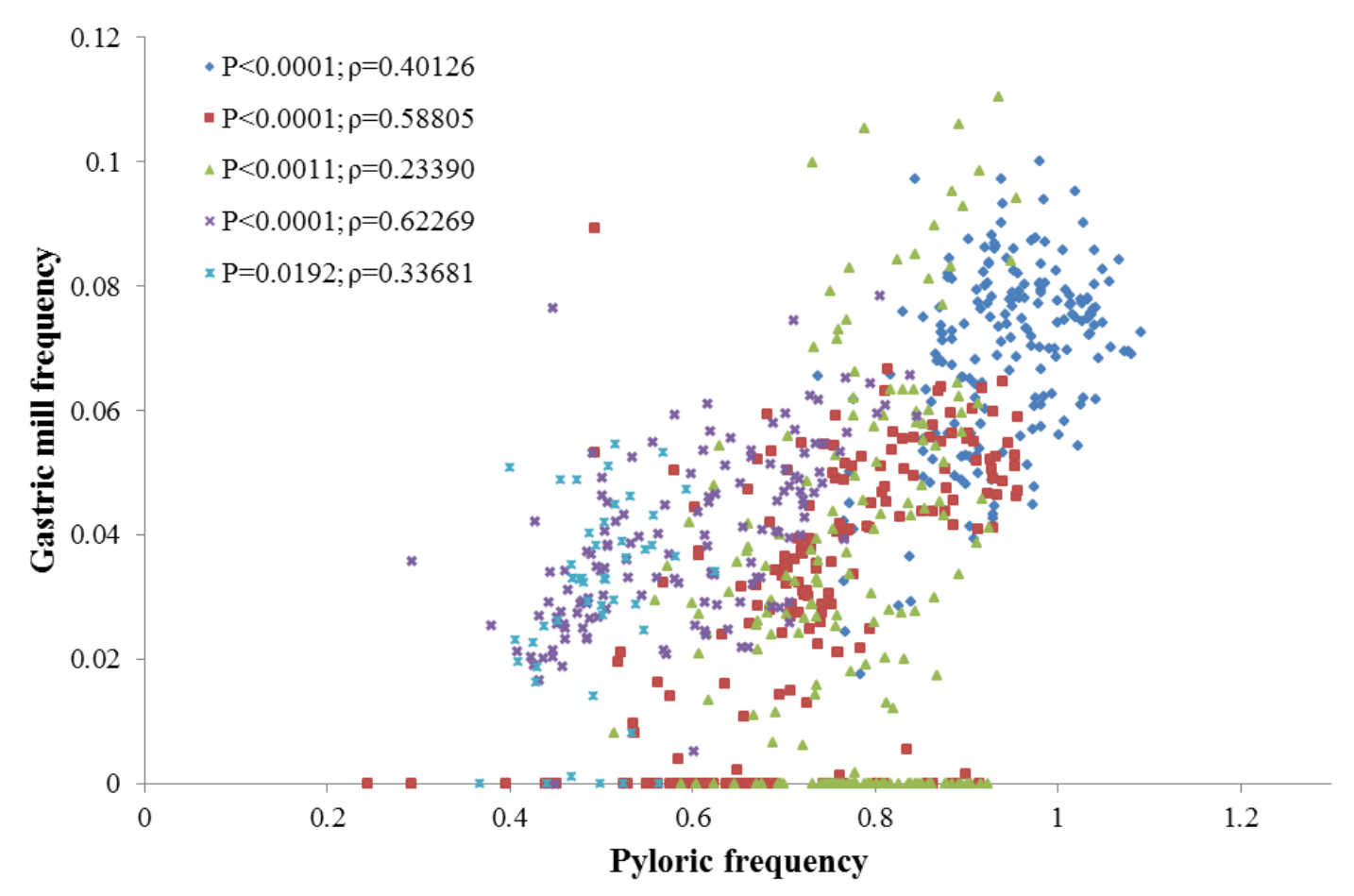

Figure 14: Correlations between gastric mill and pyloric frequencies.

Spearman rank order tests revealed significant positive correlations between gastric mill and pyloric frequencies for all animals. Different colors represent different animals. Each data point is one half hour average of the pyloric and gastric mill frequency.

\section{The Pyloric and Gastric Mill Rhythms Interact Similarly In Vivo and In Vitro}

The gastric mill and pyloric rhythms interact with one another such that in vitro the frequency of the pyloric rhythm increases when the gastric mill rhythm is active, but also decreases during bursts of LG compared with in between LG bursts. The gastric mill rhythm is episodic, i.e. it is only activated in certain modulatory condition. For example, sensory pathways activate projection neurons such as MCN1, which influence both the activity of the pyloric neurons as well as the activity of LG (Bartos and Nusbaum, 1997). 
Whether the same correlations between the two rhythms also exist in vivo where there are also sensory influences interacting with both rhythms is unclear.

To determine whether these short-term interactions exist in vivo, I compared the pyloric frequency with and without active gastric mill rhythm. I expected to find a connection between these two rhythms because in vitro projection neurons such as MCN1 can influence both the activity of the pyloric neurons as well as the activity of LG. Data used for analysis were chosen only from animals under LD conditions using a random number generator to select from a pool of 30 minute long recording files. The first ten to twenty cycles were analyzed for each file. Files that had no gastric mill activity had significantly lower pyloric frequencies than those where the gastric mill rhythm was active (Fig. 15A) (Wilcoxon signed rank test $\mathrm{P}=0.017, \mathrm{n}=20$ files per animal, $\mathrm{N}=8$ animals).

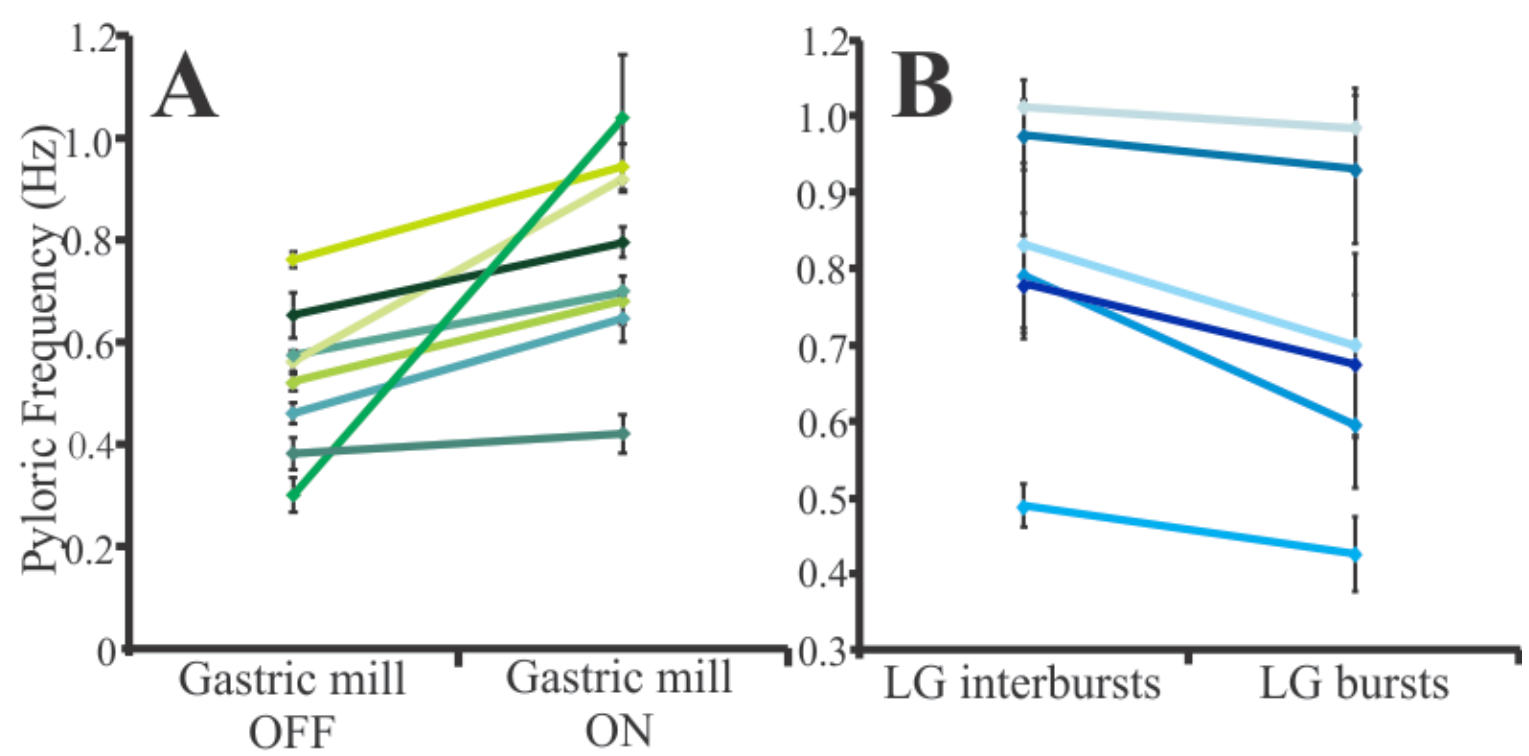

Figure 15: Pyloric and gastric mill rhythm in vivo interactions. 
A) Pyloric frequency increases when the gastric mill rhythm is active $(\mathrm{N}=8, \mathrm{p}=0.017)$. B) Pyloric frequency decreases during LG bursts $(\mathrm{N}=6, \mathrm{p}=0.014)$. Different colored lines represent different animals.

Looking more closely at the pyloric frequency during gastric mill activity, I also found that the pyloric cycles, which occur between LG bursts, have higher frequencies than those during LG bursts (Fig. 15B) (Paired t test $\mathrm{P}=0.014 \mathrm{n}=15$ cycles $\mathrm{N}=6$ animals). This indicates that the gastric mill rhythm does interact with the pyloric rhythm in vivo. This finding corresponds with in vitro findings, in which interactions between the circuits controlling the gastric mill and pyloric rhythms were shown (Bartos and Nusbaum, 1997).

While in vitro the gastric mill is only rarely spontaneously active (45\%) (Stein et al., 2005), I found that the gastric mill rhythm in vivo was active in $82.2 \%$ of all $30 \mathrm{~min}$. data files $(n=887, N=7)$. Several different types of gastric mill rhythms have been described in vitro (Blitz et al., 2004), all of which can be elicited by sensory pathways. In vivo, only two versions have been described to occur in different sensory conditions (Diehl et al., 2013). In my experiments, I found that there were at least two distinct types of gastric mill rhythms. To characterize these different types, I used the time from start to start of LG bursts to calculate the gastric mill frequency over several days. Type 1 stayed active for very long periods (multiple days in a row) and the frequency of this type of gastric mill rhythm continuously increased and decreased every $\sim 1$ hour throughout (Fig. 16 middle). Type 2 came on periodically for $\sim 20$ minutes at a time, every $\sim 5$ hours (Fig. 16 bottom). The individual LG bursts were not visually distinct from one another, 
but Type 2 gastric mill rhythms were often associated with LP inhibition (Fig. 16 bottom). Type 1 rhythms were observed in 6 out of the 7 animals tested and Type 2 was observed in 5 out of the 7 .

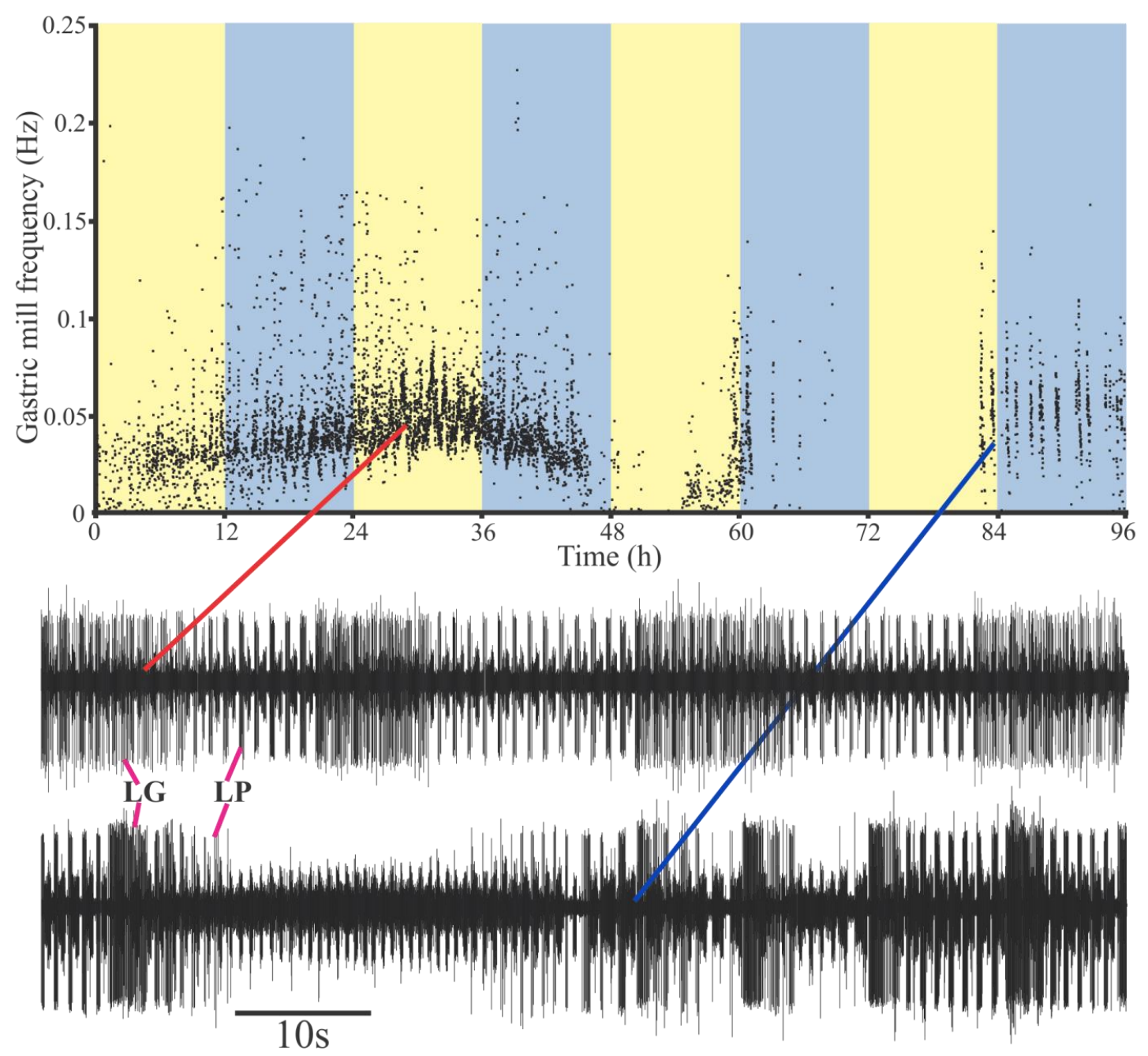

Figure 16: Example in vivo gastric mill frequency from one animal showing two types of gastric mill rhythms.

Figure shows gastric mill frequency from one animal. Top: Red line indicates Type 1: a continuously active gastric mill rhythm. Blue line indicates Type 2: a sporadically active 
gastric mill rhythm. Middle: Example $l v n$ recording used to calculate gastric mill frequency for Type 1 gastric mill rhythm. Bottom: Example $l v n$ recording used to calculate gastric mill frequency for Type 2 gastric mill rhythm with LP inhibition.

\section{Feeding Immediately Influences the Activity of the Pyloric Rhythm and Persists for Several Days}

In order to examine the short-term sensory influences capable of overriding daily patterns of rhythmicity I used food as a short-term sensory influence. Feeding resulted in a significant and long lasting increase (Fig. 17) ( $\sim 3$ days before beginning to decrease) in pyloric cycle frequency and decreased the burst duration of LP (Fig. 18) (Frequency: Paired t test $\mathrm{P}=0.003, \overline{\mathrm{y}}=0.506+/-0.110$; Burst duration: Paired t test $\mathrm{P}=0.08, \overline{\mathrm{y}}=0.246+/-0.128, \mathrm{~N}=4$ animals), which corresponds with previous findings in vivo in lobster (Clemens et al., 1998). Interestingly, feeding also decreased the duty cycle, number of spikes per burst, and the variability of the frequency as well as increased the spike frequency of LP (Fig. 18) (Paired t tests $\mathrm{P}=0.06, \overline{\mathrm{y}}=0.033+/-0.014$; $\mathrm{P}=0.026, \overline{\mathrm{y}}=1.485+/-0.422 ; \mathrm{P}=0.09, \overline{\mathrm{y}}=0.086+/-0.070 ; \mathrm{P}=0.014, \overline{\mathrm{y}}=10.156+/-2.116$ respectively) This is the first demonstration that changes in duty cycle of a pyloric neuron can be modified by sensory stimulation other than temperature. 


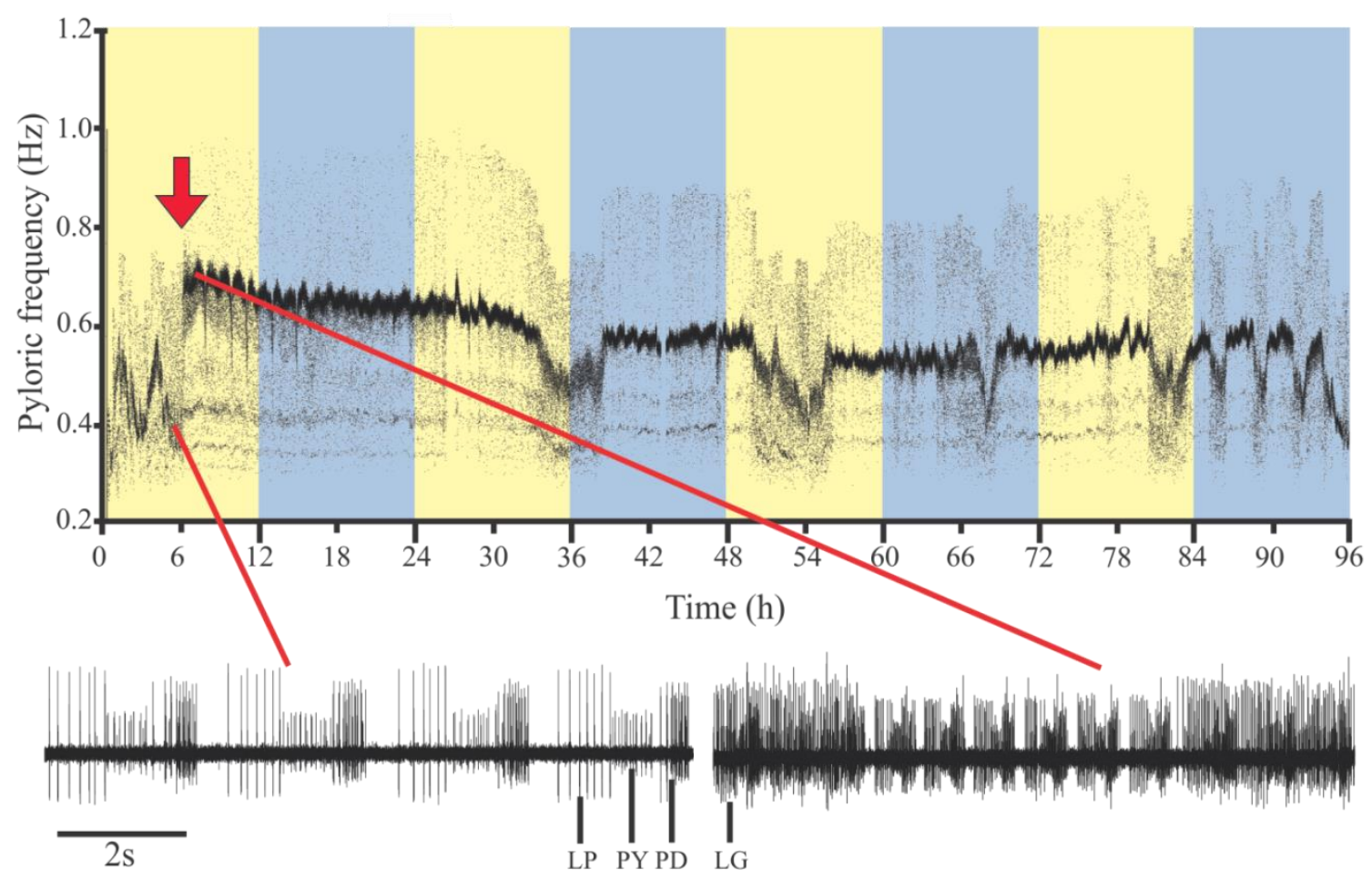

Figure 17: Example in vivo pyloric frequency after feeding.

Figure shows pyloric frequency over 4 days under a LD light cycle in one animal after feeding. Yellow area indicates light, blue indicates dark. Each data point represents the frequency of one pyloric cycle. Lower traces show example pyloric rhythms before and after feeding. Red arrow indicates when feeding occurred. 


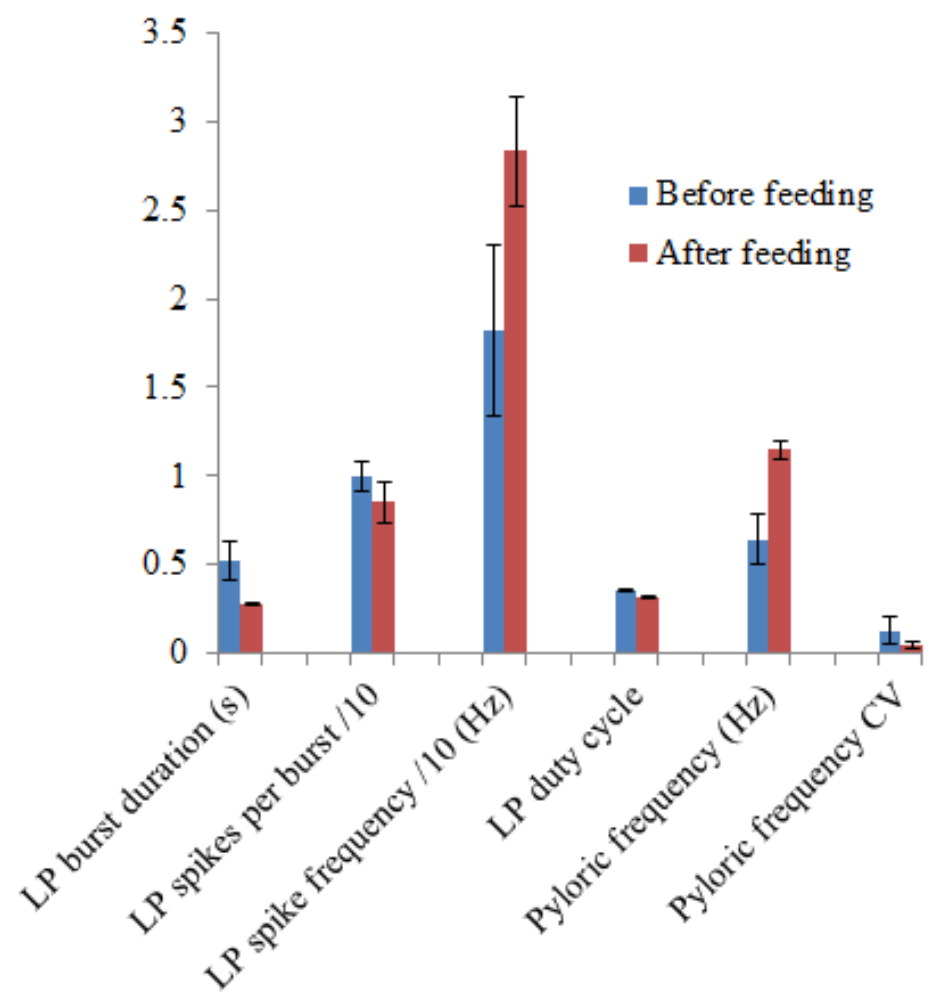

Figure 18: Different aspects of the pyloric rhythm before and after feeding.

All variable were significantly different before and after feeding. Paired T test results were as follows. Burst duration: $\mathrm{P}=0.08, \overline{\mathrm{y}}=0.246+/-0.128$; Spikes per burst: $\mathrm{P}=0.026$, $\overline{\mathrm{y}}=1.485+/-0.422$; Spike frequency $\mathrm{P}=0.014, \overline{\mathrm{y}}=10.156+/-2.116$; Duty cycle: $\mathrm{P}=0.06$, $\overline{\mathrm{y}}=0.033+/-0.014$; Pyloric frequency: $\mathrm{P}=0.003, \overline{\mathrm{y}}=0.506+/-0.110$; Coefficient of variation: $\mathrm{P}=0.09, \overline{\mathrm{y}}=0.086+/-0.070 . \mathrm{N}=4$ animals.

\section{Non-canonical Pyloric Rhythms Occur Sporadically and can be Associated with Gastric Mill Rhythms}

Finally, while the pyloric rhythm is very stereotyped in vitro (Bucher et al. 2005) and always comprises the three phases (PD, PY and LP), several non-canonical rhythms occurred in vivo. These rhythms deviated from the standard triphasic pyloric 
rhythm observed in vitro such that either one or more of the neurons was inactive (Fig. 18 middle left, bottom right), the neurons were active out of order (Fig. 19 top right, middle right, bottom left), or a neuron was active longer than usual (Fig. 19 bottom left, top right, middle right). Bouts of non-canonical activity occurred $\sim 3 \%$ of the time and lasted anywhere from one cycle $(\sim 1 \mathrm{~s})$ to 1 hour, but always return to the canonical structure. No obvious pattern of occurrence was observed other than one type of non-canonical rhythm, which occurred during Type 2 gastric mill rhythms and inhibited LP (Fig. 19 middle left).

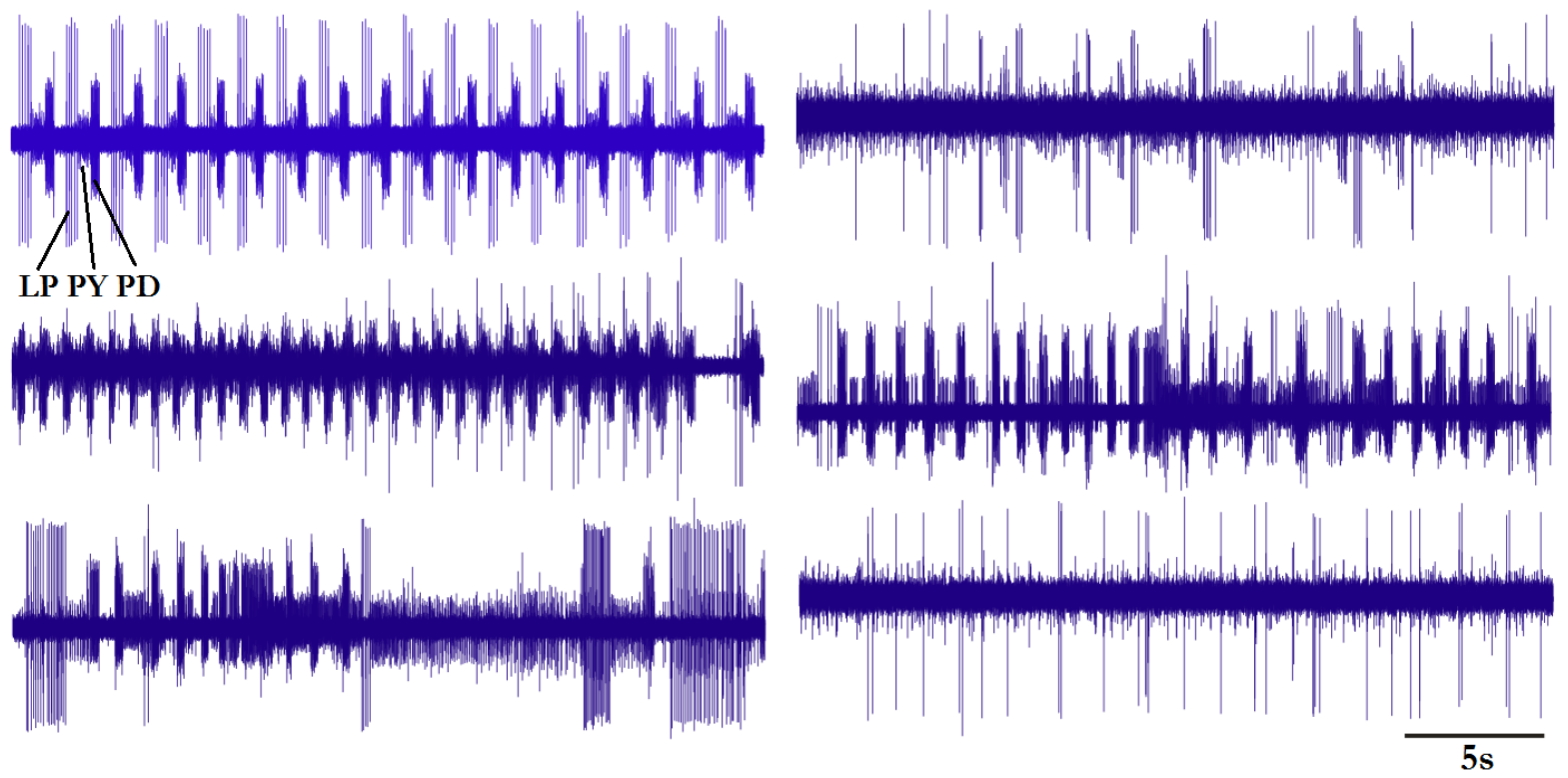

Figure 19: A typical in vivo canonical pyloric rhythm as well as examples of noncanonical pyloric rhythms.

Top left shows canonical rhythm, all others show non-canonical rhythms 


\section{CHAPTER IV}

\section{DISCUSSION}

This is the first study to link the motor output of the STNS in the Jonah crab with multiple environmental influences in vivo. Jonah crabs did not exhibit consistent daily patterns of locomotion under controlled lab conditions; however the frequency of the pyloric and gastric mill rhythms were dependent on the light cycle, such that during periods where the light changed the frequencies of both rhythms increased. Even though there was a significant effect of light on both rhythms' frequencies, the amount of variability observed within individuals overshadowed those changes. The duty cycle of LP was independent of the frequency of the rhythm and was also not affected by any of the controlled environmental cues including light, temperature, $\mathrm{pH}$, and osmolarity. Rather, the duty cycle remained constant throughout the recording time.

The pyloric and gastric mill rhythms were highly correlated and showed similar intercircuit interactions in vivo as were previously reported in vitro (Bartos and Nusbaum, 1997). The environmental stimulus, which had the greatest impact on the rhythms' activities, was feeding. Feeding altered not only the frequencies of both rhythms, but also the structure of the pyloric rhythm. In a few cases, non-canonical rhythm structures such as those that occur after artificial introduction of neuromodulators in vitro (Marder, 2012) were also observed. 


\section{Daily Rhythmicity of Locomotion}

Different species of crustaceans undergo different types of circadian rhythms including diurnal, nocturnal, crepuscular, or circatidal patterns (Novak, 2004). Inconsistency in these types of activity patterns even within species is not uncommon and there is presently some debate over what may actually entrain their locomotor rhythms (Dugaw et al., 2009). Green crabs, a close relative of the Jonah crab have been reported to have a large amount of variability in activity patterns including both nocturnal and circatidal activity patterns (Lynch and Rochette, 2007; Novak, 2004). Two hypotheses have been proposed to explain the variability between individuals' daily patterns of locomotor activity in this species: The first, entitled the circalunidian-clock hypothesis suggests that there are two 24.8 hour antiphasic clocks that drive the rhythmicity of activity. These clocks are entrained by the tides, but because the difference between the lunar (tidal) and solar period is only 50 minutes ( 0.8 hours) it is impossible to distinguish the two. In other words it could be either be two antiphasic solar clocks, or one lunar and one solar clock, which entrain locomotion (Palmer, 2000). The two solar clocks must be antiphasic to accommodate the two peaks observed each day, if they were in phase the peaks would occur at the same time and so would only occur once per day. The second hypothesis is very similar to the first and suggests that locomotor activity is controlled through the interaction of one 24 hour circadian clock and one 12.4 hour circatidal clock (Naylor, 1996). However neither of these hypotheses fully accounts for the amount of variability observed between individuals (Dugaw et al., 2009). 
One explanation for why all the animals in the current study showed different patterns of rhythmicity during the LD condition is that they may have inhabited different niches. Crabs can be both the prey and predators of other crustaceans, such as lobster depending on their relative sizes (Hudon and Lamarche, 1989). It may be necessary for these animals to adapt their daily patterns of activity throughout their lives as they grow to best avoid predation and at the same time expose themselves to the best foraging opportunities. This has not been observed for Jonah crabs, but one species of salmon is known to feed at different times of day depending on how big they are in order to avoid predators (Kadri et al., 1997). It has also been reported that diel behavior in decapod natantia (shrimps and prawns) is linked with morphology, so that species who share the same daily swimming behaviors also share morphological characteristics (Aguzzi et al., 2008). Jonah crabs have been shown to have a size and sex dependence in terms of depth distribution, but no data was available for locomotor activity (Haefner, 1977). Therefore size and morphology is one route that could be taken in the future to explain some of the variability seen for these crabs' locomotor activity.

There is unfortunately no easy way of identifying the age of our animals before beginning an experiment, but correlation between size, age or morphology and activity may provide some insight into whether or not any of these physical characteristic are a contributing factor in the governance of daily rhythmicity.

An additional factor, which may have had an impact on locomotor activity, was that in lab conditions these animals are housed in minimalist enclosures with no 
opportunity for foraging. This may have effected their motivation to move as often as they would under more natural conditions.

Lastly, it has long been known that diet composition can influence behavior (Preedy et al., 2011). Although in my experiments animals were starved prior to surgery, there is no way of knowing how long ago their last meal was or what it consisted of. In rats for example, increasing the protein composition of their diets by only $18 \%$ significantly altered their activity so that during dark periods they went through periods of intense activity followed by quiescence, whereas under the low protein diet, the mice were almost continuously active with no periods of quiescence (Chiel and Wurtman, 1981). This indicates that diet directly affects circadian activity patterns, however the long-term (weeks) influence of diet on crustacean activity is currently unknown.

Based on our overall observations of locomotion in Jonah crabs, it is unlikely any truly innate clock exists in this species to control the timing of locomotion. There was no consistent pattern of activity across animals. Further, those individuals who did appear to either have crepuscular or diurnal activity patterns did not persist under DD conditions. It is possible that if enough animals' activities were averaged a circadian rhythmicity of locomotion would emerge, but in the case of these experiments, it is either very week or needs constant entrainment through the sun, moon, or tides in order to have any substantial influence on any individual animal's behavior. It seems that when Jonah crabs are isolated away from their natural habitat, and environmental cues that any rhythmicity in their locomotion previously observed in the wild no longer exists. 


\section{Daily Rhythmicity of Motor Patterns in the STNS}

One would typically assume that any patterns in locomotor behavior would be correlated with foraging and thus chewing (gastric mill rhythm) and filtration (pyloric rhythm), but this was not the case. The lack of a consistent daily rhythm for locomotion was independent of daily rhythmicity for the frequency of the pyloric and gastric mill rhythms. The gastric mill and pyloric rhythm frequencies, unlike locomotion, showed a significant increase during dawn and dusk compared to midday and midnight. This indicates that different pathways are likely responsible for determining the activity of locomotion and of the STNS. In vertebrate systems the somatic nervous system, which controls voluntary behaviors such as locomotion utilizes different transmitters to activate those pathways than the autonomic nervous system, which controls involuntary behaviors such as digestion (Brown, 2011). Decapod crustaceans have neural structures analogous to the vertebrate autonomic nervous system used to control internal organs (gastric mill and pylorus) (Shuranova et al., 2006), so the crustacean digestive system could potentially also be governed by different neuromodulation than the somatic nervous system (locomotor behavior). This could explain why there were different patterns of activity for locomotion and the STNS.

My data indicate that the pyloric and gastric mill rhythms are not controlled by an innate circadian rhythm. Because the increase in frequency for both rhythms during the hours surrounding dawn and dusk did not persist under constant light or dark conditions, it was likely only in response to the lights changing and not the time of day. Because the lights did not gradually shift on or off, but instead abruptly switched between the two 
states, one might conclude that the response observed was simply due to an abrupt and unexpected sensory stimulus; that the animals were startled by the sudden change. In lobsters it was found that when the animals were in darkness and suddenly exposed to light, the activity of the gastric mill rhythm was suppressed immediately after (Fleischer, 1980). However this effect only lasted for 10 minutes following light exposure and the changes I observed lasted several hours. Even if the observed increase was a startle response, any effect this would have had on the STNS would be very short and thus overshadowed by the many additional hours of pyloric and gastric mill activity surrounding dawn and dusk. This included the three hours prior to the light change, so it is thus more likely an entrained response to the time of day and not a startle response directly following the light change.

The study completed by Fleischer (1980) also looked at the effect of eyestalk hormones on the gastric mill rhythm. Eyestalk hormones, which are peptides released from the sinus gland in response to light, can alter the electrical activity of motoneurons (Arechiga et al., 1977). Fleischer found that application of eyestalk hormone to the STG decreases gastric mill activity (cycles per hour) for one hour while ablating the eyestalks increased gastric mill activity for as long as 50 hours (Fleischer, 1980). This indicated that light sensation has some control over the activity of the gastric mill rhythm and that the release of eyestalk hormone has an inhibitory effect on the gastric mill rhythm. It is thus surprising that no significant difference was found between light and dark in the activity of the gastric mill rhythm for the Jonah crab in the present study. However, the effect Fleischer observed when applying eyestalk hormone only lasted one hour. Consequently, changes in gastric mill frequency would thus only be obvious directly 
following a light change. Such changes would only be detectable when comparing dawn to dusk because those were the only times of day, which included the hour directly after the light change. However, I found no significant difference between dawn and dusk, indicating that a light-driven inhibition of the gastric mill rhythm was absent in Jonah crab. Alternatively, it is possible that such an inhibition could not be accounted for in my experiments, since the gastric mill rhythm was not always active at the time of the light change.

\section{Long-term Pyloric and Gastric Mill Frequency Variability}

Although it is important to look across many animals to decipher long-term patterns of activity, when considering individual days within individual animals I have shown that slower patterns can be completely overshadowed by faster variations in activity. Many tidal crustaceans have innate circatidal rhythmicities to their behavior (Akiyama, 2014; Rebach, 1985; Lynch and Rochette, 2007; Williams and Naylor, 1967; Hough and Naylor, 1992), but how important is that long-term rhythmicity when so many other sensory drivers are capable of altering the behavior of an animal? Animals are constantly exposed to sensory influences like sounds, smells, and temperature, which are able to override daily patterns of activity (Cox et al., 2006; McGaw and Naylor, 1992; Williams and Naylor, 1967). In vivo even when I controlled temperature, $\mathrm{pH}$, osmolarity and light, the frequencies of the pyloric and gastric mill rhythms varied substantially. While not all sensory influences an animal can respond to can be controlled, none of the variables mentioned above correlated with the changes in pyloric and gastric mill frequency. Consequently, the sensory influences I did control are unlikely to explain the 
amount of variability of the pyloric and gastric mill frequencies seen within individuals. A possible explanation is that other sensory influences, which I did not control for can cause large amounts of variability. This could include noise outside of the tanks, small amounts of light reaching the animals from outside the tanks, pockets of water with slightly different chemical compositions, proprioceptive feedback or other physiological processes interacting with STNS activity.

\section{The Structure of the Pyloric Rhythm Remains Stable across Pyloric Frequencies}

It is necessary to maintain stability and robustness of motor output to produce adequate behavioral performance. This can apply to different aspects of motor output depending on the behavior. There are some general parameters for rhythmic systems that must be maintained in order to support function while others may be changed. One such parameter, which is often maintained, is the phase relationships between the different units of neurons or muscles which control motor behaviors. For example, to produce swimming in lamprey, appropriate phase relationships must be maintained (Cohen et al., 1992). The frequency of behaviors must also sometimes be regulated or maintained depending on the situation, if for example the frequency of a hummingbird's wingbeat was not maintained it would likely fall.

The pyloric rhythm has been shown to maintain phase relationships in response to environmental perturbations. One example of this is the effect of temperature. Increasing temperature increases the frequency of the pyloric rhythm in vivo and in vitro. It does not however alter the structure of the pyloric rhythm (Soofi et al., 2014; Tang et al., 2012). Bucher et al. (2005) also found that in juvenile and adult preparations, although the size 
of the pyloric neurons and the frequency of the pyloric rhythm varied greatly, the phase relationships were very similar across animals. This demonstrates the STNS's ability to maintain stable motor output in the face of physiological and environmental disturbances. Accordingly, in my experiments I found that LP duty cycle remained constant while frequency varied substantially. Apparently, the speed of this particular rhythmic behavior can change with little or no consequence to the structure of the pattern.

\section{The Pyloric and Gastric Mill Rhythms Interact Similarly In Vivo and In Vitro}

The pyloric and gastric mill circuits have long been known to be interconnected and influence one another in vitro (Bartos and Nusbaum, 1997; Stein et al., 2005; Beenhakker et al., 2004). My results now show that this is also the case in vivo.

Several projection neurons can elicit different versions of the gastric mill rhythm in vitro (Stein 2009), but the effects of projection neurons on the pyloric and gastric mill rhythms have not been characterized in vivo. There is also no definite way to determine from single extracellular recordings, which circuit's activities alter the other. We can speculate that modulatory projection neurons such as MCN1 as well as the gastric mill neurons influence pyloric activity. Figure 20 shows a simplified circuit diagram of some of the known connections between the pyloric and gastric mill circuits that contribute to the gastric mill rhythm elicited by the modulation from MCN1 (Bartos and Nusbaum, 1997). 


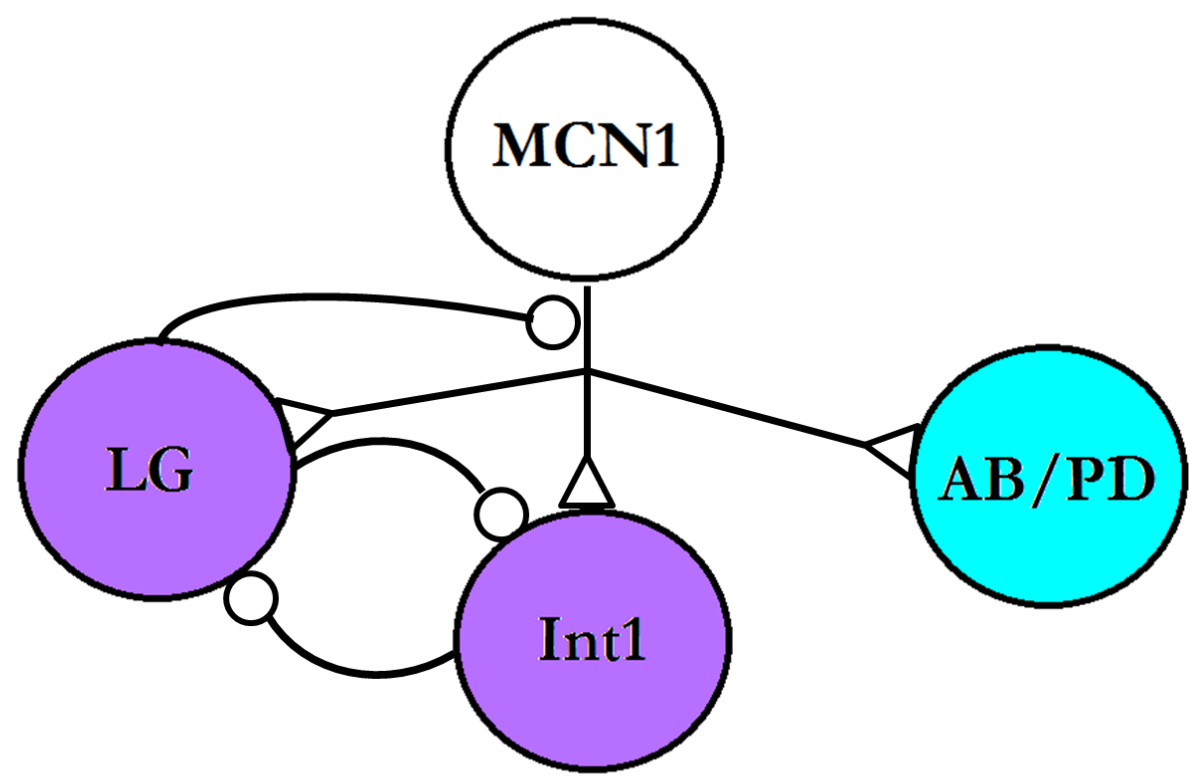

Figure 20: Simplified schematic of some of the connections between pyloric and gastric mill circuit neurons.

MCN1 is a modulatory projection neuron, LG and Int1 are gastric mill CPG neurons, and $\mathrm{AB}$ and $\mathrm{PD}$ are pyloric pacemaker neurons. Triangles represent excitatory synapses. Circles represent inhibitor synapses.

There are three important pyloric circuit interactions: The first is that the gastric mill rhythm, represented by a half center oscillator (LG and Int1) can be excited by MCN1 and that MCN1 also excites the pyloric neurons, represented by a conditional pacemaker (AB/PD). Secondly, when LG is active it presynaptically inhibits MCN1 at the synapse between $L G$ and $\mathrm{AB}$, which decreases excitation of $\mathrm{AB} / \mathrm{PD}$ (Bartos and Nusbaum, 1997). Third, the AB neuron strongly inhibits Int1. As a result, Int1 is periodically inhibited by $\mathrm{AB}$ at the frequency of the pyloric rhythm. Int 1 also inhibits LG, 
so LG is consequently disinhibited at the frequency of the pyloric rhythm (Nadim et al., 1998).

As a result of these connections, when MCN1 excites the gastric mill rhythm it also excites the pyloric rhythm and the frequencies of both rhythms increase. Within these bouts of MCN1 activity, the activity of LG alternates with that of Int1. When LG is active it presynaptically inhibits MCN1, which decreases excitation to the pyloric neurons and the frequency of the pyloric rhythm decreases. During LG interbursts, MCN1 is no longer presynaptically inhibited by LG and so the pyloric neurons continue to receive excitation from MCN1 and return to their higher frequency.

My data are consistent with the idea that similar mechanisms contribute to the interactions between the gastric and pyloric circuits in vivo. Yet, different types of gastric mill rhythms were not distinguished in my analysis. The gastric mill rhythm can be activated by other projection neurons such as modulatory commissural neuron 5 (MCN5) and modulatory commissural neuron 7 (MCN7) (Hedrich et al., 2009; Nusbaum et al., 2001). I observed two main types of gastric mill rhythms. Type 1 was the most common. Type 1 was likely an MCN1/CPN2 driven rhythm because it did not inhibit LP and MCN1/CPN2 driven rhythm can be activated by two separate pathways in vitro (Beenhakker and Nusbaum, 2004; Blitz et al., 2004). Type 2 was likely an MCN5 driven rhythm as it tended to be accompanied by inhibition of LP, which has been shown to occur with MCN5 activation in vitro (Norris et al., 1996).

One difference between the gastric mill rhythm in vivo and in vitro that I did observe was that while the gastric mill rhythm is not always active in vitro (45\% active) 
(Stein et al., 2005), it was almost always active in vivo (82\% active). It is reasonable to assume that this is because the gastric mill rhythm is activated by sensory neurons and most of the senses no longer exist in vitro. Alternatively, the level of excitation could differ in vivo and in vitro such that gastric mill rhythms are more difficult to elicit in vitro due to the absence of excitatory neuromodulators or modulatory pathways.

\section{Feeding Immediately Influences the Structure and Frequency of the Pyloric Rhythm}

The pyloric frequency increased immediately after feeding, but the more interesting result was that feeding decreased the duty cycle and burst duration, and increased the spike frequency of LP. This is notable because phase relationships are typically maintained (Soofi et al., 2014; Tang et al., 2012; Bucher et al., 2005) and changes to those relationships may indicate changes in behavioral performance. The means by which such phase relationships of the pyloric rhythm can be modulated have been extensively studied (Marder, 2012), but whether these alterations have behavioral relevance has not been established. The gastric mill rhythm, for example, has been shown exhibit different structures, which produce different behavioral outputs in vivo (Diehl et $a l ., 2013$ ), so this could potentially occur for the pyloric rhythm as well. These animals were fed squid, but it is possible that had a different type of food been introduced the resulting change in structure of the rhythm would be different than that observed for digesting squid. That is, particular changes in pyloric rhythm structure may serve to adapt to the type of food being processed. It would be interesting in the future to determine whether different types of food elicit different pyloric rhythms or if the observed changes in structure are at all dependent on food presence or type. 
While frequency increased, the variability of the pyloric frequency decreased in response to feeding. It is possible that there is an optimal frequency for filtering whereas without food the frequency may not need to remain stable and is not restricted within a specific, ideal range. In fact, there are indications that neuromodulator release from projection neurons may influence variability in the pyloric frequency. Descending modulatory projection neurons such as MCN1 are activated by food stimuli (Beenhakker et al., 2004) and directly affect pyloric frequency. Whether proctolin release from MCN1 indeed reduces the variability of the pyloric frequency is currently subject of a study conducted in the Stein lab. Preliminary data indicate that proctolin release supports neuronal oscillations and reduces the effects of (sensory) perturbations on frequency (Stein, personal communication). One of the mechanisms by which proctolin release may affect the pyloric rhythm is by regulating leak currents in the pyloric pacemaker neurons. Zhao et al. (2010) showed that when neuromodulatory inputs to the pyloric neurons are blocked, a reduction of the leak conductance in any single neuron within the pyloric pacemaker group can not only recover the pacemaker activity of that neuron, but also the entire pyloric network. When released, peptide modulators like proctolin elicit a specific conductance in STG neurons (Swensen and Marder, 2000) that acts as a negative leak, effectively reducing the leak conductance and (re-)stabilizing the pyloric rhythm.

\section{Non-canonical Pyloric Rhythms Occur Sporadically and can be Associated with Gastric Mill Rhythms}

Non-canonical rhythms do not typically occur in vitro (Bucher et al., 2005). There have been no studies reporting naturally occurring non-canonical rhythms in vitro or in 
vivo thus far. Some potential sources of non-canonical rhythms include hormones (Marder, 2012) and modulatory input neurons (Stein, 2009). In addition, sensory input/feedback and intercircuit interactions may also be responsible for non-canonical rhythms, although none of the sensory or intercircuit interaction I described in this study were linked to non-canonical rhythms other than the type where LP was inhibited. That particular non-canonical rhythm, which exhibited LP inhibition, was concomitant with Type 2 gastric mill rhythms. LP inhibition is also the hallmark of MCN5 activation (Norris et al., 1996), although it is unclear whether MCN5 indeed contributed to the observed pattern in vivo.

One other possible reason for non-canonical rhythms could be damage to the nerve that occurred during surgery. This seems unlikely though as all animals showed large stretches of the canonical rhythm, and always recovered completely from bouts of non-canonical rhythms.

\section{Conclusions}

In this study we determined some of the long and short-term environmental influences on rhythmic motor patterns produced by the STNS. We found that although a slight light-driven activity pattern exists in vivo for the pyloric and gastric mill rhythms, it cannot explain the large variability observed for both rhythms over long-periods. Other sensory influences as well as intercircuit interactions were responsible for the majority of activity fluctuations observed in vivo. 


\section{REFERENCES}

Aguzzi, J., Costa, C., Antonucci, F., Company, J. B., Menesatti, P. and Sarda, F. (2009). Influence of diel behaviour in the morphology of decapod natantia. Biol J Linn Soc. 96.3, 517-532.

Akiyama, T. (2014). Circatidal and Circadian Rhythms in Crustacean Swimming Behavior. In Annual, Lunar, and Tidal Clocks. (ed. H. Numata and B. Helm), pp. 65-90. Japan: Springer.

Alcedo, J., Maier, W. and Ch'ng, Q. (2010). Sensory influence on homeostasis and lifespan: molecules and circuits. Adv Exp Med Biol. 694, 197-210.

Allen, M.J. and Godenschwege, T.A. (2010). Electrophysiological recordings from the Drosophila giant fiber system (GFS). Cold Spring Harb Protoc. 7, 5453.

Antri, M., Fénelon, K. and Dubuc, R. (2009). The contribution of synaptic inputs to sustained depolarizations in reticulospinal neurons. J Neurosci. 4, 114051 .

Arbas, E.A. and Calabrese, R.L. (1984). Rate modification in the heartbeat central pattern generator of the medicinal leech. J Comp Physiol A Sens Neural Behav Physiol. 155.6, 783-794.

Ayali, A. and Harris-Warrick, R.M. (1999). Monoamine control of the pacemaker kernel and cycle frequency in the lobster pyloric network. J Neurosci. 19.15, 6712-22.

Bantscheff, M., Schirle, M., Sweetman, G., Rick J. and Kuster, B. (2007). Quantitative mass spectrometry in proteomics: a critical review. Anal Bioanal Chem. 389.4, 1017-31.

Bartos, M., Manor, Y., Nadim, F., Marder, E. and Nusbaum, M.P. (1999). Coordination of fast and slow rhythmic neuronal circuits. J Neurosci. 19.15, 6650-60.

Bartos, M. and Nusbaum, M.P. (1997). Intercircuit control of motor pattern modulation by presynaptic inhibition. J Neurosci. 17.7, 2247-56.

Beenhakker, M.P., Blitz, D.M. and Nusbaum, M.P. (2004). Long-lasting activation of 
rhythmic neuronal activity by a novel mechanosensory system in the crustacean stomatogastric nervous system. J Neurophysiol. 91.1, 78-91.

Beenhakker, M.P. and Nusbaum, M.P. (2004). Mechanosensory activation of a motor circuit by coactivation of two projection neurons. 24.30, 6741-50.

Ben-Shlomo, R. and Kyriacou, C.P. (2002). Circadian rhythm entrainment in flies and mammals. Cell Biochem Biophys. 37.2, 141-56.

Billimoria, C.P., Li, L. and Marder, E. (2005). Profiling of neuropeptides released at the stomatogastric ganglion of the crab, Cancer borealis with mass spectrometry. J Neurochem. 95.1, 191-9.

Binder, M.D. and Hirokawa, N. (2009). Encyclopedia of neuroscience. (ed. M.D. Binder, N Hirokawa and U. Windhorst). Berlin, Heidelberg: Springer.

Blitz, D.M., Beenhakker, M.P. and Nusbaum, M.P. (2004). Different sensory systems share projection neurons but elicit distinct motor patterns. J Neurosci. 24.50, 11381-90.

Blitz, D.M. and Nusbaum, M.P. (2011). Neural circuit flexibility in a small sensorimotor system. Curr Opin Neurobiol. 21.4, 544-52.

Brown, T.A. (2012). Neurophysiology. In Rapid Review Physiology (ed. E.F. Goljan), pp. 30. Philadelphia, PA: Elsevier Mosby

Buchanan, J.T. (2011). Spinal locomotor inputs to individually identified reticulospinal neurons in the lamprey. J Neurophysiol. 106.5, 2346-57.

Bucher D., Prinz A.A and Marder E. (2005). Animal-to-animal variability in motor pattern production in adults and during growth. J Neurosci. 25.7, 1611-9.

Chen, R., Ma, M., Hui, L., Zhang, J. and Li, L. (2009). Measurement of neuropeptides in crustacean hemolymph via MALDI mass spectrometry. J Am Soc Mass Spectrom. 20.4, 708-18.

Chiel H.J., and Wurtman R.J. (1981). Short-term variations in diet composition change the pattern of spontaneous motor activity in rats. Science. 213.4508, 6768.

Clemens, S., Massabuau, J.C., Legeay, A., Meyrand, P. and Simmers, J. (1998). In vivo modulation of interacting central pattern generators in lobster stomatogastric ganglion: influence of feeding and partial pressure of oxygen. J Neurosci. 18.7, 2788-99

Clemens, S., Combes, D., Meyrand, P. and Simmers, J. (1998). Long-term expression 
of two interacting motor pattern-generating networks in the stomatogastric system of freely behaving lobster. J Neurophysiol. 79.3, 1396-408.

Cohen A.H., Ermentrout G.B., Kiemel T., Kopell N., Sigvardt K.A. and Williams, T.L. (1992). Modelling of intersegmental coordination in the lamprey central pattern generator for locomotion. Trends Neurosci. 15.11, 434-8.

Conway, B.A., Hultborn, H. and Kiehn, O. (1987). Proprioceptive input resets central locomotor rhythm in the spinal cat. Exp Brain Res. 68.3, 643-56.

Cox, T. M., Ragen, T. J., Read, A. J., Vos, E., Baird, R. W., Balcomb, K., Barlow, J., Caldwell, J., Cranford, T., Crum, L., et al. (2006). Understanding the impacts of anthropogenic sound on beaked whales. J Cetacean Res Manage. 7.3, 177-187.

Diehl, F., White, R.S., Stein, W. and Nusbaum, M.P. (2013). Motor circuit-specific burst patterns drive different muscle and behavior patterns. J Neurosci. 33.29, 12013-29.

Dugaw, C.J., Honeyfield, R., Taylor, C.M. and Verzi, D.W. (2009). Modeling activity rhythms in fiddler crabs. Chronobiol Int. 26.7, 1355-68.

Feldman, J.L. and Del Negro, C.A. (2006). Looking for inspiration: new perspectives on respiratory rhythm. Nat Rev Neurosci. 7.3, 232-42.

Fleischer, A. G. (1981). The effect of eyestalk hormones on the gastric mill in the intact lobster, Panulirus interruptus. J Comp Physiol. 141.3, 363-368.

Fontanini, A. and Katz, D.B. (2008). Behavioral states, network states, and sensory response variability. J Neurophysiol. 100.3, 1160-8.

Gutierrez, G.J. and Grashow, R.G. (2009). Cancer borealis stomatogastric nervous system dissection. J Vis Exp. 25, 1207.

Haefner Jr, P. A. (1977). Aspects of the biology of the jonah crab, Cancer borealis Stimpson, 1859 in the mid-Atlantic Bight. J Nat Hist. 11.3, 303-320.

Hardin, P.E. and Panda, S. (2013). Circadian timekeeping and output mechanisms in animals. Curr Opin Neurobiol. 23.5, 724-31.

Harris-Warrick, R. M. (1992). Dynamic biological networks: the stomatogastric nervous system. (ed. R.M. Harris-Warrick, E. Marder, A.I. Selverston, and M. Moulins). MIT press.

Harris-Warrick, R.M. (2011). Neuromodulation and flexibility in Central Pattern Generator networks. Curr Opin Neurobiol. 21.5, 685-92. 
Harris-Warrick, R.M., and Marder, E. (1991). Modulation of neural networks for behavior. Annu. Rev. Neurosci. 14.1, 39-57.

Hedrich, U.B., Diehl, F. and Stein, W. (2011). Gastric and pyloric motor pattern control by a modulatory projection neuron in the intact crab Cancer pagurus. $\mathrm{J}$ Neurophysiol. 105.4, 1671-80.

Heinzel, H.G. and Selverston, A.I. (1988). Gastric mill activity in the lobster III Effects of proctolin on the isolated central pattern generator. J Neurophysiol. 59.2, 566-85.

Heinzel, H.G., Weimann, J.M. and Marder, E. (1993). The behavioral repertoire of the gastric mill in the crab, Cancer pagurus: an in situ endoscopic and electrophysiological examination. J Neurosci. 13.4, 1793-803.

Hermann, C., Yoshii, T., Dusik, V. and Helfrich-Förster, C. (2012). Neuropeptide F immunoreactive clock neurons modify evening locomotor activity and free-running period in Drosophila melanogaster. J Comp Neurol. 520.5, 970-87.

Hooper, S.L. and Marder, E. (1984). Modulation of a central pattern generator by two neuropeptides, proctolin and FMRFamide. Brain Res. 305.1, 186-91.

Hough, A. R. and Naylor, E. (1992). Endogenous rhythms of circatidal swimming activity in the estuarine copepod Eurytemora affinis (Poppe). J Exp Mar Biol Ecol. 161.1, 27-32.

Hudon, C. and Lamarche, G. (1989). Niche segregation between American lobster. Mar. Ecol. Prog. Ser. 52, 155-168.

\section{Li, L., Pulver, S.R., Kelley, W.P., Thirumalai, V., Sweedler, J.V. and Marder, E.} (2002). Orcokinin peptides in developing and adult crustacean stomatogastric nervous systems and pericardial organs. J Comp Neurol. 444.3, 227-44.

Lynch, B. and Rochette, R. (2007). Circatidal rhythm of free-roaming sub-tidal green crabs, Carcinus maenas, revealed by radio-acoustic positional telemetry. Crustaceana. 80, 345-355.

Marder, E. (2014). [online] Blogs.brandeis.edu. Available at: http://blogs.brandeis.edu/marderlab/files/2012/01/modulatorsCancer.jpg [Accessed 26 May. 2014].

Marder, E. (2012). Neuromodulation of neuronal circuits: back to the future. Neuron. 76.1, 1-11. 
Marder, E., Bucher, D., Schulz, D.J. and Taylor, A.L. (2005). Invertebrate central pattern generation moves along. Curr Biol. 15.17, R685-99.

Marder, E. and Bucher, D. (2007). Understanding circuit dynamics using the stomatogastric nervous system of lobsters and crabs. Annu Rev Physiol. 69, 291-316.

Marder, E. and Calabrese, R.L. (1996). Principles of rhythmic motor pattern generation. Physiol Rev. 76.3, 687-717.

Marder, E., Hooper, S.L. and Siwicki, K.K. (1986). Modulatory action and distribution of the neuropeptide proctolin in the crustacean stomatogastric nervous system. J Comp Neurol. 243.4, 454-67.

McGaw, I. J. and Naylor, E. (1992). Salinity preference of the shore crab Carcinus maenas in relation to coloration during intermoult and to prior acclimation. J Exp Mar Biol Ecol, 155.2, 145-159.

Nadim, F., Manor, Y., Nusbaum, M.P. and Marder, E. (1998). Frequency regulation of a slow rhythm by a fast periodic input. J Neurosci. 18.13, 5053-67.

Naylor, E. (1996). Crab clockwork: the case for interactive circatidal and circadian oscillators controlling rhythmic locomotor activity of Carcinus maenas. Chronobiol Int. 13.3, 153-61.

Norris, B.J., Coleman, M.J. and Nusbaum, M.P. (1996). Pyloric motor pattern modification by a newly identified projection neuron in the crab stomatogastric nervous system. J Neurophysiol. 75.1, 97-108.

Nusbaum, M.P. (1994). Presynaptic control of neurones in pattern-generating networks. Curr Opin Neurobiol. 4.6, 909-14.

Nusbaum, M.P. and Beenhakker, M.P. (2002). A small-systems approach to motor pattern generation. Nature. 417, 343-50.

Nusbaum M.P., Blitz D.M., Swensen A.M., Wood D. and Marder E. (2001). The roles of co-transmission in neural network modulation. Trends Neurosci. 24.3, 146-54.

Palmer, J.D. (2000). The clocks controlling the tide-associated rhythms of intertidal animals. Bioessays. 22.1, 32-7.

Preedy, V. R., Watson, R. R. and Martin, C. R. (2011). Handbook of behavior, food and nutrition. (ed. V.R. Preedy, R.R. Watson and C.R. Martin), New York: Springer Science \& Business Media. 
Pulver, S.R. and Marder, E. (2002). Neuromodulatory complement of the pericardial organs in the embryonic lobster, Homarus americanus. J Comp Neurol. 451.1, 79-90.

Rebach, S. (1985). Rhythmicity under constant conditions in the rock crab. Cancer irroratus. B Mar Sci. 36, 454-566

Richards, K.S. and Marder, E. (2000). The actions of crustacean cardioactive peptide on adult and developing stomatogastric ganglion motor patterns. J Neurobiol. 44.1, 31-44.

Skiebe, P. and Schneider, H. (1994). Allatostatin peptides in the crab stomatogastric nervous system: inhibition of the pyloric motor pattern and distribution of allatostatin-like immunoreactivity. J Exp Biol. 194, 195-208.

Smarandache, C., Hall, W.M. and Mulloney, B. (2009). Coordination of rhythmic motor activity by gradients of synaptic strength in a neural circuit that couples modular neural oscillators. J Neurosci. 29.29, 9351-60.

Soofi, W., Goeritz, M.L., Kispersky, T.J., Prinz, A.A., Marder, E. and Stein, W. (2014). Phase maintenance in a rhythmic motor pattern during temperature changes in vivo. J Neurophysiol. 111.12, 2603-13.

Stanewsky, R. (2003). Genetic analysis of the circadian system in Drosophila melanogaster and mammals. J Neurobiol. 54.1, 111-47.

Stein, W. (2009). Modulation of stomatogastric rhythms. J Comp Physiol A Neuroethol Sens Neural Behav Physiol. 195.11, 989-1009.

Stein, W., DeLong, N.D., Wood, D.E. and Nusbaum, M.P. (2007). Divergent cotransmitter actions underlie motor pattern activation by a modulatory projection neuron. Eur J Neurosci. 26.5, 1148-65.

Stein W., Eberle C.C. and Hedrich U.B. (2005). Motor pattern selection by nitric oxide in the stomatogastric nervous system of the crab. Eur J Neurosci. 21.10, 2767-81

Strauss, J. and Dircksen, H. (2010). Circadian clocks in crustaceans: identified neuronal and cellular systems. Front Biosci 15, 1040-74.

Taghert, P.H. and Nitabach, M.N. (2012). Peptide neuromodulation in invertebrate model systems. Neuron. 76.1, 82-97.

Thirumalai, V., Prinz, A.A., Johnson, C.D. and Marder, E. (2006). Red pigment 
concentrating hormone strongly enhances the strength of the feedback to the pyloric rhythm oscillator but has little effect on pyloric rhythm period. J Neurophysiol. 95.3, 1762-70.

Williams, B.G. and Naylor, E. (1967). Spontaneously induced rhythm of tidal periodicity in laboratory-reared Carcinus. J Exp Biol. 47.2, 229-34.

Zhao S., Golowasch, J. and Nadim, F. (2010). Pacemaker neuron and network oscillations depend on a neuromodulator-regulated linear current. Front Behav Neurosci. 4, 21.

Zhdanova, I.V., Lynch, H.J. and Wurtman, R.J. (1997). Melatonin: a sleep-promoting hormone. Sleep. 20.10, 899-907. 